\title{
MODIFICACIONES RECIENTES DE LA CUBIERTA NIVAL Y EVOLUCIÓN DE LA VEGETACIÓN SUPRAFORESTAL EN LA SIERRA DE GUADARRAMA, ESPAÑA: EL PUERTO DE LOS NEVEROS
}

\author{
A. GARCÍA ROMERO(1), J. MUÑOZ JIMÉNEZ(2) \\ (1) Departamento de Geografía Física. Instituto de Geografía. \\ Universidad Nacional Autónoma de México. México D.F. \\ (2) Departamento de Análisis Geográfico Regional y Geografía Física. \\ Facultad de Geografía e Historia. Universidad Complutense. Madrid \\ Correo electrónico de contacto: juliom@ghis.ucm.es
}

\begin{abstract}
RESUMEN. Se estudia un área de 118 ha correspondiente al Puerto de los Neveros, un collado de $2.100 \mathrm{~m}$ de altura que se abre en la cuerda de Peñalara (Montes Carpetanos) entre las altas cuencas del Lozoya y del Eresma; dicho collado fue reconocido durante siglos como uno de los ámbitos mejor dotados de la Sierra de Guadarrama para la acumulación y la permanencia de la nieve y también para la explotación de la misma. Con el objeto de avanzar en el conocimiento de la relación entre las modificaciones climáticas recientes y los cambios registrados en la cubierta vegetal de las áreas supraforestales del Sistema Central español se analiza, mediante la interpretación de sucesivas coberturas de fotografía aérea, la dinámica espacial de las formaciones que componen la cubierta vegetal del área y se aprecia la correlación de ésta con la evolución de los parámetros termométricos y nivométricos registrados en la cercana estación meteorológica de Puerto de Navacerrada a lo largo del período 1951-2006. El significativo valor de los coeficientes obtenidos permite afirmar que la cubierta vegetal del collado ha sido sensible a las variaciones climáticas acaecidas en dicho período, entre las que destacan el aumento de las temperaturas invernales, la reducción de los aportes nivales y el acortamiento del tiempo de permanencia de la nieve sobre el suelo, y ha respondido a ellas reduciendo la extensión de los ventisqueros, de los pastizales y de los matorrales abiertos y ampliando la superficie ocupada por matorrales densos.
\end{abstract}

ABSTRACT. The purpose of this study is to add more insight to the relationship between recent climate change and modifications in plant cover in supratimberline areas of Spain's Central Mountain Range. A 118 hectare study site was chosen at Puerto de los Neveros pass $(2100 \mathrm{~m}$ ) located on the ridge Peñalara (Montes 
Carpetanos), and between the high basins of the Lozoya and Eresma rivers. Historically, the pass is associated with the most abundant and long lasting snow accumulations in the Guadarrama Mountains, and with frequent use of the snow by local populations. A collection of sequenced aerial photographs of the plant cover was used to interpret the vegetation's spatial dynamics in relation to the evolution of thermal and snow depth variables recorded for the period 1951-2006 at the weather station at Puerto de Navacerrada. The significant value of the resulting coefficients confirms that plant cover at Puerto de los Neveros has been greatly affected by climate change, particularly by warmer winters, less snowfall and shorter snow duration, which have contributed to the shrinking surface area of snow hollows, high meadows and open shrublands and to the expansion of dense bush.

Palabras clave: Cambios climáticos, vegetación supraforestal, nieve, Sistema Central Español, Sierra de Guadarrama.

Key words: Climate changes, supraforest vegetation, snow, Spanish Central System, Sierra de Guadarrama.

Enviado el 24 de septiembre de 2009 Aceptado el 4 de febrero de 2010

\section{Antecedentes, objetivos y metodología}

Entre los efectos que se atribuyen al reciente calentamiento del clima se encuentra la disminución del tiempo de permanencia de la nieve sobre el suelo en las áreas de alta montaña. Diversos autores la han reconocido y han observado que en las últimas décadas los fenómenos y procesos ligados a la nivación han registrado notables retrocesos, tanto en extensión superficial como en intensidad, apreciando que dichos retrocesos se correlacionan de forma significativa con el "cambio climático global". Se ha considerado también que, al ser la cubierta vegetal de los ámbitos supraforestales muy sensible a las modificaciones del clima y estar altamente condicionada por la duración de la cobertura nival (Billings y Bliss, 1959; Daly, 1984; Körner, 1999), la distribución y la evolución reciente de la vegetación pueden constituir un indicador de la incidencia de la modificación del clima y de las variaciones del área de actuación de los procesos asociados a la permanencia de la nieve en dichos ámbitos (Ballantyne, 1985; Nyberg, 1991).

En el caso de la sierra de Guadarrama, cuyos sectores más elevados pueden considerarse representativos de la alta montaña mediterránea del centro de la Península Ibérica (Sanz, 1988), estudios recientes revelan que en ella la cobertura nival se correlaciona con un reducido y específico número de coberturas vegetales y que dichas coberturas, lo mismo que el resto de las formaciones supraforestales, han sufrido en los últimos años unos reajustes dimensionales importantes coincidiendo con la modificación de algunas variables termométricas y nivométricas (Palacios y García, 1997a y 1997b; Palacios y Andrés, 2000; Palacios, Andrés y Luengo, 2003; Marcos y Palacios, 2004; Andrés y Palacios, 2004; Muñoz y García Romero, 2004). Estos estudios se han 
centrado hasta ahora en el macizo de Peñalara (Montes Carpetanos) y en el entorno del Alto de las Guarramillas (Cuerda Larga) y se han referido a cumbres o a cabeceras fluviales emplazadas en laderas de gran altura y pendiente relativamente fuerte (Sanz-Elorza, Dana, González y Sobrino, 2003; Palacios y Andrés, 2007; Pintado y García, 2007; Andrés, García Romero, Muñoz y Palacios, 2007a y 2007b).

Entroncando con esta línea de investigación, este estudio tiene como objetivo avanzar en el conocimiento de la relación entre las modificaciones climáticas recientes y los cambios registrados en la cubierta vegetal de las áreas supraforestales del Sistema Central español, centrando ahora el análisis en un espacio diferente: un collado de $2.096 \mathrm{~m}$ de altura y topografía más suave reconocido durante siglos como uno de los ámbitos mejor dotados de la Sierra de Guadarrama para la acumulación y la permanencia de la nieve, así como para la explotación de la misma (Fernández Troyano, 1990). Con el objeto de establecer y valorar la indicada relación se ha realizado, mediante trabajo de campo la definición de las 16 facies o formaciones que componen la cubierta vegetal, se las ha agrupado en 7 tipos básicos y se ha delimitado y medido su área respectiva en imágenes fotográficas correspondientes a seis fechas: 1956, 1972, 1984, 1990, 1998 y 2007. De otro lado, se han sometido a tratamiento estadístico los datos del período 19512006, referentes a 19 parámetros climáticos, proporcionados por la Estación de Observación Meteorológica del Puerto de Navacerrada, perteneciente a la Red Principal y situado en un emplazamiento análogo (aunque de menor altura: $1.892 \mathrm{~m}$ ) a cinco km de distancia del Puerto de los Neveros (Servicio Meteorológico Nacional, 1976; Alarcón, Martínez y Martínez Molina, 1984; Instituto Nacional de Meteorología, 1995 y 2002; Agencia Estatal de Meteorología, 2001-2006).

Partiendo de la hipótesis de que la dimensión relativa y la distribución espacial de los componentes de la cubierta vegetal han de reflejar en mayor o menor medida las condiciones climáticas reinantes en los años inmediatamente anteriores a la fecha en la que son captadas por la fotografía aérea, el indicado período de registro meteorológico se ha dividido en cinco tramos delimitados por las fechas de realización de los vuelos utilizados y se han obtenido los valores medios de los parámetros climáticos en cada uno de ellos. A continuación, estos valores medios de tramo se han correlacionado con las superficies ocupadas por los componentes de la cubierta vegetal al final de cada uno de ellos, definiendo y cuantificando de este modo las relaciones entre las variables climáticas y la estructura de la vegetación supraforestal a lo largo de la segunda mitad del siglo XX y en los primeros años del XXI.

Para realizar de forma precisa la localización y delimitación de las áreas correspondientes a los componentes de la cubierta vegetal se ha utilizado como apoyo una Ortofoto Digital de 1998 y los fotogramas de los cinco vuelos -una vez interpretadoshan sido corregidos geométricamente y georreferenciados con el apoyo operativo del Sistema de Información Geográfica "ILWIS 3.0" (U.G.S.D., 2001). Las bases de datos así generadas han sido exportadas a un programa estadístico para hallar las superficies de los distintos tipos de vegetación y establecer sus índices de cambio. Por su parte, la información climática ha sido tratada con el programa de cálculo "Microsoft Excel", utilizando líneas polinómicas para apreciar las tendencias de las 18 variables tomadas en 
consideración y el Coeficiente de Correlación de Pearson para valorar su correlación con la superficie de las formaciones vegetales.

\section{Caracterización y encuadre del área de estudio}

El territorio estudiado es un cuadrado de 118 ha de extensión, que corresponde, como se ha dicho, a un collado situado en el sector más elevado de la sierra de Guadarrama. Este collado, conocido como Puerto de los Neveros está enmarcado, al N, por el Alto del Nevero (2.139 m) y, al S, por la del Risco Claveles $(2.389 \mathrm{~m})$, sirviendo de paso entre dos laderas empinadas y de casi $1.000 \mathrm{~m}$ de desnivel: una orientada al $\mathrm{W}$ y vertiente al río Eresma; otra orientada al E y vertiente al río Lozoya. El área delimitada para el análisis incluye la divisoria de aguas en el tramo correspondiente al puerto (que tiene su punto más bajo a $2.096 \mathrm{~m}$ ) y las áreas inmediatas a ella de una y otra ladera. Dentro de su ámbito - modelado en su práctica totalidad sobre materiales neísicos profundamente alterados- la altura varía entre $\operatorname{los} 2.170$ y $\operatorname{los} 1.980 \mathrm{~m}$ y la pendiente tiene un valor medio algo inferior al $30 \%$ (Fig. 1; Fotos 1 y 2).

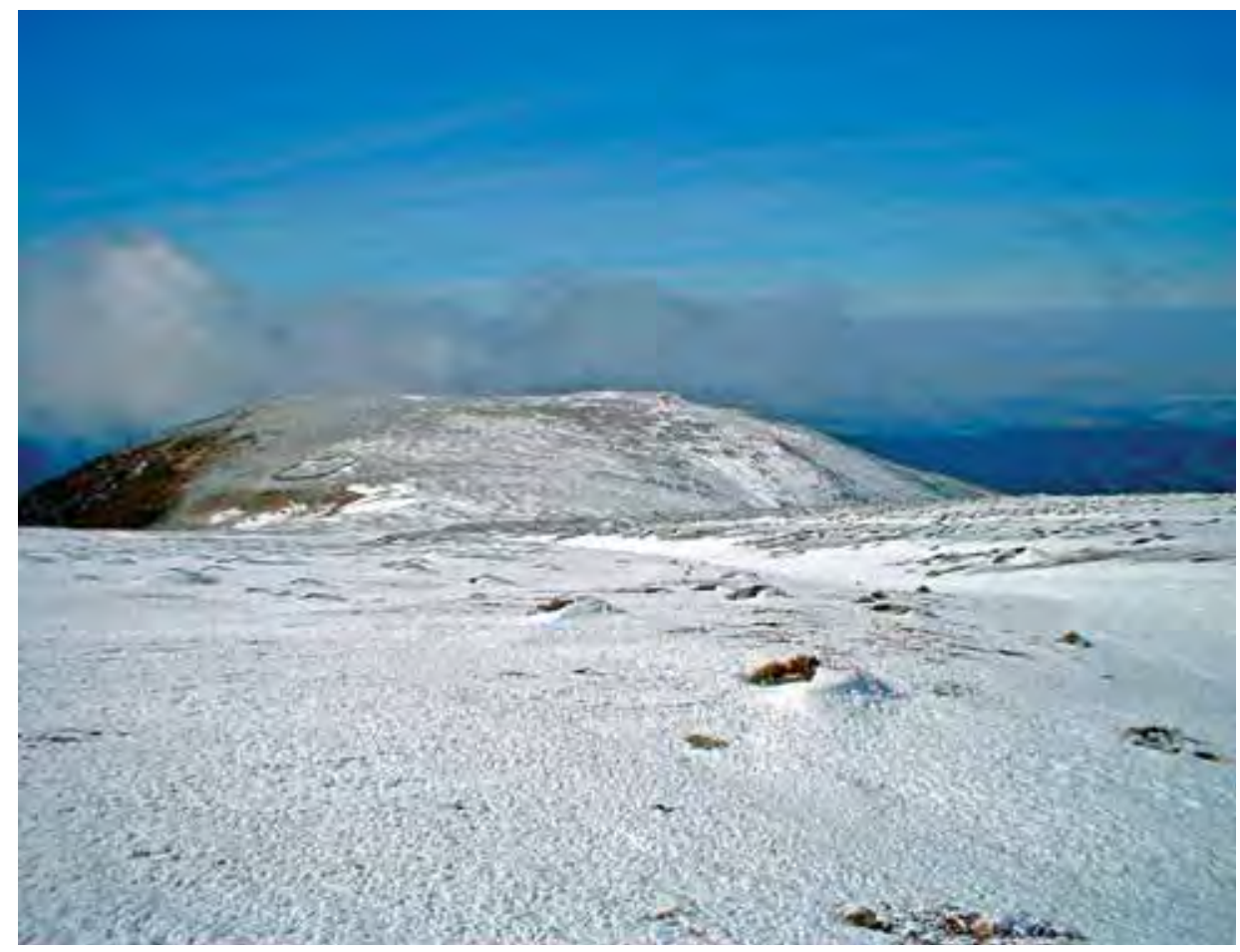

Foto 1. El Puerto de los Neveros, visto desde el Sur, a finales de invierno. Al fondo el Alto del Nevero; a la izquierda, cabecera del arroyo de la Chorranca (vertiente al Eresma); a la derecha, cabecera del arroyo de Hoyo Claveles (vertiente al Lozoya). 


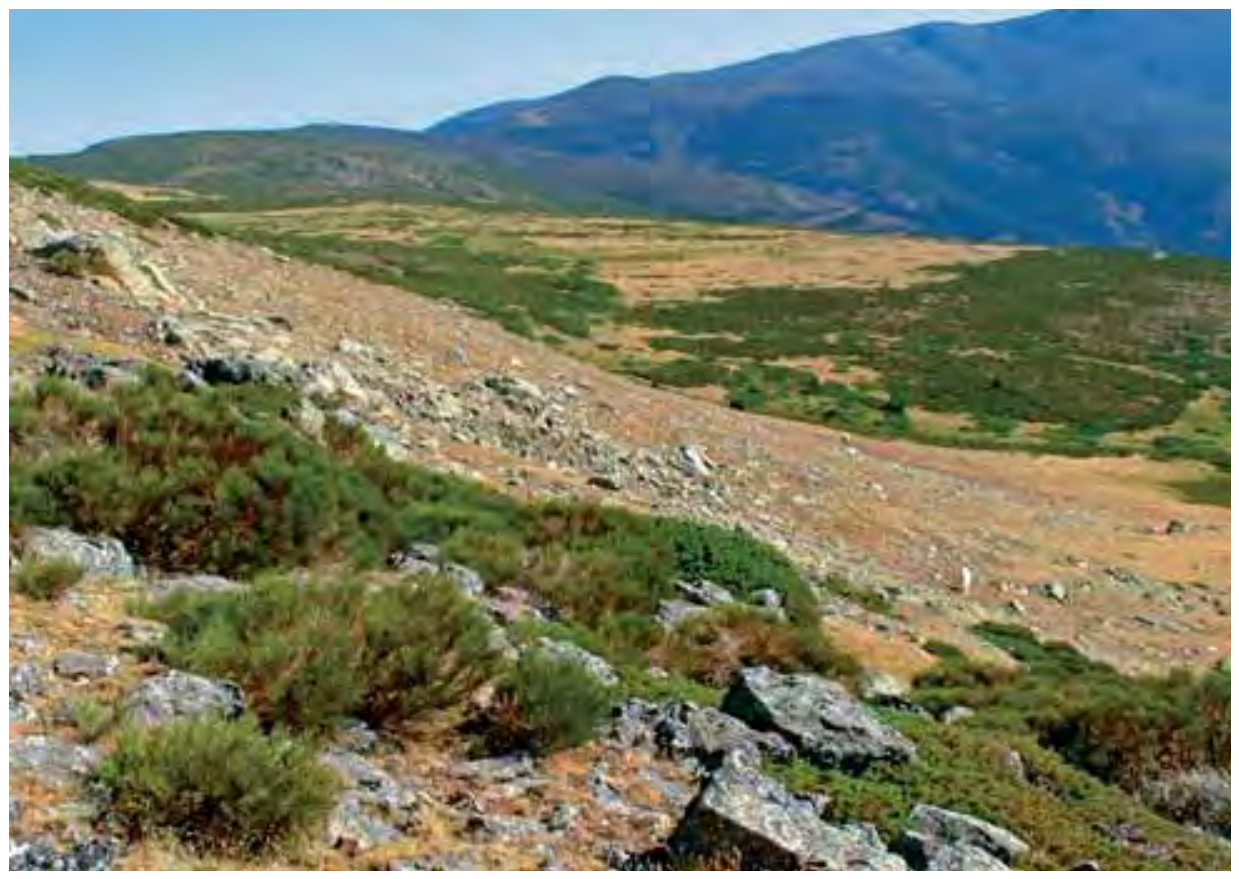

Foto 2. El Puerto de los Neveros, visto desde el Sur, en verano. Al fondo el Alto del Nevero y su enlace con la alineación de los Montes Carpetanos; a la derecha, vertiente al Lozoya.

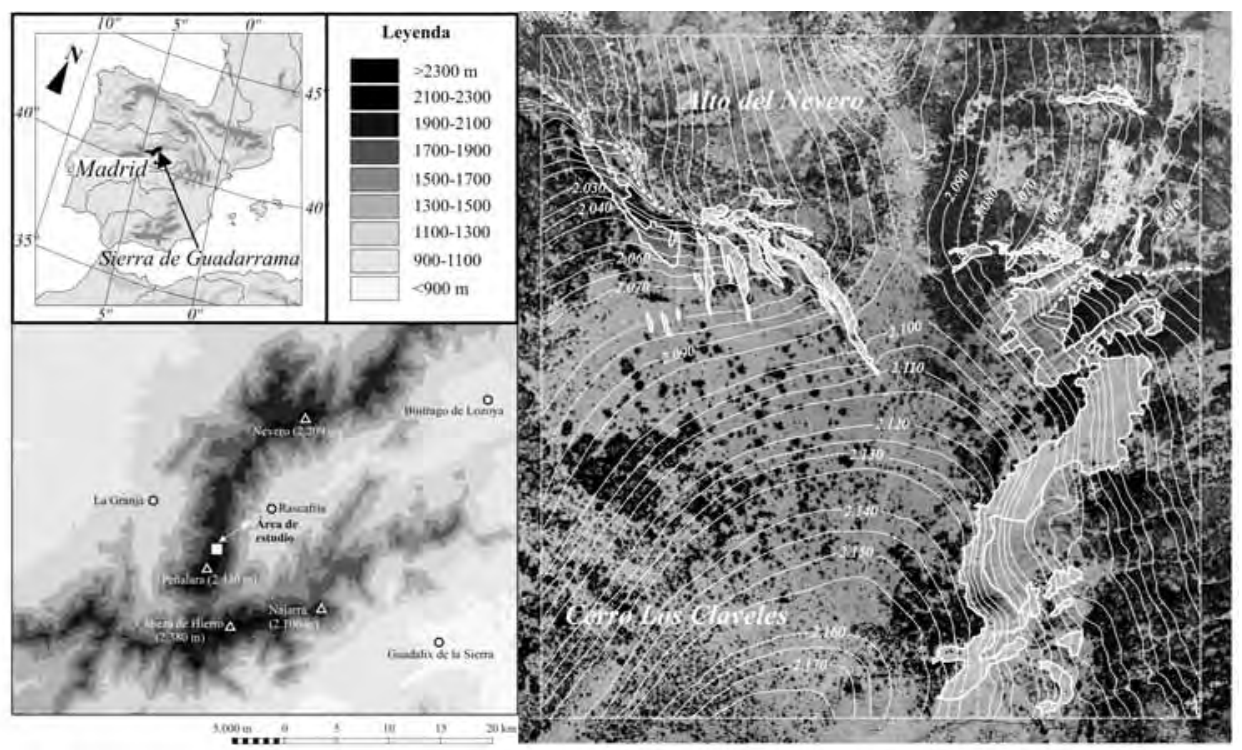

Figura 1. Localización y topografía del Puerto de los Neveros en la porción central de la Sierra de Guadarrama. Sobre la ortoimagen se indican las áreas de distribución de los neveros o ventisqueros en 2007. 
Dada su elevación, en el collado la temperatura media anual se sitúa actualmente entre $\operatorname{los} 6,0^{\circ}$ y $\operatorname{los} 7,0^{\circ}$ y se reciben cada año por término medio $1.100 \mathrm{~mm}$ de agua distribuidos en alrededor de 100 días de precipitación, produciéndose ésta en forma de nieve en la mitad de los casos; pero lo más importante es que, debido a que la temperatura media anual de las mínimas no sobrepasa los 3,0 $0^{\circ}$, las mínimas medias mensuales son negativas a lo largo de cinco meses (de diciembre a abril) y las medias mensuales sólo sobrepasan $\operatorname{los} 10,0^{\circ}$ en cuatro meses (de junio a septiembre), la nieve puede mantenerse sobre el suelo durante algo más de 90 días por término medio (Durán Montejano, 2007). No obstante, en algunos enclaves particularmente favorecidos por la orientación y la topografía -los "neveros" o "ventisqueros"- la permanencia de ésta es mucho mayor, pudiendo acercarse en promedio a los 200 días/año (Palacios, Andrés y Luengo, 2004; Marcos y Palacios, 2004).

En conformidad con los parámetros climáticos actuales, propios del horizonte superior del Piso Oromediterráneo, la cubierta vegetal potencial no tiene carácter forestal y está constituida hoy mayoritariamente por matorrales monoespecíficos o mixtos de Cytisus carpetanus ("piorno") y/o Juniperus alpina (enebro rastrero o "jabino") (Fernández González, 1991; Gavilán, Fernández y Blasic, 1998; Rivas-Martínez et al., 1999; Izquierdo, 2007). En los sectores más altos y expuestos estos matorrales son sustituidos por pastizales psicroxerófilos dominados por Festuca curvifolia (“joraga”) y en los fondos más protegidos y húmedos por praderas higrófilas de Nardus stricta ("cervuno"), siendo la vegetación muy escasa en los roquedales y en las pedreras, donde la roca neísica se muestra sin alterar (Sanz, 1979; Rivas-Martínez et al., 1989). En las áreas particularmente favorables para la acumulación y la persistencia de la nieve ("neveros" o "ventisqueros") la cubierta vegetal corresponde, por su parte, a laxas formaciones herbáceas con alta presencia de especies quionófilas como Sedum candollei, Rumex acetosella, Gentiana lutea y Senecio pyrenaicus (Palacios y García, 1997a).

Desde el punto de vista administrativo, el puerto de los Neveros marca el límite entre el municipio segoviano de La Granja o San Ildefonso y el madrileño de Rascafría, perteneciendo el área de estudio a terrenos de titularidad pública de los mismos que en la actualidad, al igual que los espacios supraforestales que la circundan, son objeto de un aprovechamiento muy poco intenso y casi exclusivamente ganadero (Valenzuela Rubio, 1977; Mas, 1998). Anteriormente, desde comienzos del siglo XIX en que se produce la crisis definitiva de la ganadería lanar transhumante vinculada a la Mesta hasta las primeras décadas del XX, esta actividad ganadera estante y extensiva -que incluía presencia de otros tipos de ganado (caprino, ovino) y la quema periódica de piornalesera algo más importante (Casas Torres, 1943) y se combinaba con la explotación de los ventisqueros para abastecer de nieve a las ciudades y "reales sitios" próximos; dicha explotación está totalmente extinguida en el período analizado (Corella, 1988), y la quema de matorrales se ha hecho muy esporádica.

\section{Definición de los grandes tipos o facies de vegetación y análisis de su evolución superficial}

El reconocimiento directo del terreno, que se ha realizado en varias visitas (llevadas a cabo siempre en el mes de septiembre) a partir del año 2004, ha permitido dife- 
renciar en el área hasta 16 tipos elementales de cubierta vegetal, de los cuales 6 son de carácter herbáceo (pastizales, herbazales) y 10 de carácter prioritariamente arbustivo o subarbustivo (matorrales); sólo 1, introducido por el hombre, tiene naturaleza forestal (bosque de repoblación). Teniendo en cuenta las similitudes de su composición y de su significado ecológico, estos tipos o componentes elementales se han agrupado en los 7 grandes tipos genéricos que se describen a continuación y cuya evolución superficial -obtenida de la interpretación de las fotos aéreas de 1956, 1972, 1984, 1990, 1998 y 2007- igualmente se indica (Tabla 1) (Fig. 2).

Tabla 1. Superficie ocupada por los grandes tipos de vegetación en las fechas correspondientes a las coberturas de fotografía aérea utilizadas.

\begin{tabular}{|l|c|c|c|c|c|c|}
\hline & $\mathbf{1 9 5 6}$ & $\mathbf{1 9 7 2}$ & $\mathbf{1 9 8 4}$ & $\mathbf{1 9 9 0}$ & $\mathbf{1 9 9 8}$ & $\mathbf{2 0 0 7}$ \\
\hline $\begin{array}{l}\text { 1. Herbazales/Pastizales muy abiertos } \\
\text { de roquedales y pedreras }\end{array}$ & $0,96 \mathrm{~h}$ & $1,01 \mathrm{~h}$ & $1,38 \mathrm{~h}$ & $1,36 \mathrm{~h}$ & $1,35 \mathrm{~h}$ & $1,39 \mathrm{~h}$ \\
\hline $\begin{array}{l}\text { 2. Herbazales/Pastizales abiertos } \\
\text { de ventisqueros }\end{array}$ & $0,81 \%$ & $0,86 \%$ & $1,17 \%$ & $1,15 \%$ & $1,14 \%$ & $1,18 \%$ \\
\hline 3. Pastizales densos psicroxerófilos & $24,36 \mathrm{~h}$ & $15,93 \mathrm{~h}$ & $12,75 \mathrm{~h}$ & $10,88 \mathrm{~h}$ & $8,98 \mathrm{~h}$ & $8,45 \mathrm{~h}$ \\
& $42,48 \mathrm{~h}$ & $40,38 \mathrm{~h}$ & $30,19 \mathrm{~h}$ & $27,28 \mathrm{~h}$ & $26,74 \mathrm{~h}$ & $25,56 \mathrm{~h}$ \\
& $36,00 \%$ & $34,22 \%$ & $25,58 \%$ & $23,13 \%$ & $22,67 \%$ & $20,82 \%$ \\
\hline 4. Pastizales muy densos higrófilos & $9,85 \mathrm{~h}$ & $12,22 \mathrm{~h}$ & $9,61 \mathrm{~h}$ & $8,71 \mathrm{~h}$ & $9,43 \mathrm{~h}$ & $9,62 \mathrm{~h}$ \\
& $8,35 \%$ & $10,36 \%$ & $8,15 \%$ & $7,38 \%$ & $7,99 \%$ & $8,15 \%$ \\
\hline 5. Matorrales abiertos y muy abiertos & $34,81 \mathrm{~h}$ & $32,12 \mathrm{~h}$ & $34,59 \mathrm{~h}$ & $34,54 \mathrm{~h}$ & $32,85 \mathrm{~h}$ & $30,17 \mathrm{~h}$ \\
& $29,50 \%$ & $27,22 \%$ & $29,31 \%$ & $29,27 \%$ & $27,85 \%$ & $25,57 \%$ \\
\hline 6. Matorrales densos & $5,29 \mathrm{~h}$ & $16,08 \mathrm{~h}$ & $29,23 \mathrm{~h}$ & $34,80 \mathrm{~h}$ & $38,22 \mathrm{~h}$ & $42,54 \mathrm{~h}$ \\
& $4,48 \%$ & $13,63 \%$ & $24,77 \%$ & $29,49 \%$ & $32,38 \%$ & $36,05 \%$ \\
\hline 7. Bosques abiertos de repoblación & $0,25 \mathrm{~h}$ & $0,25 \mathrm{~h}$ & $0,25 \mathrm{~h}$ & $0,43 \mathrm{~h}$ & $0,43 \mathrm{~h}$ & $0,43 \mathrm{~h}$ \\
& $0,21 \%$ & $0,21 \%$ & $0,21 \%$ & $0,36 \%$ & $0,36 \%$ & $0,36 \%$ \\
\hline
\end{tabular}

\subsection{Herbazales/Pastizales muy abiertos de roquedales y pedreras}

Aparecen en el terreno y en las imágenes como áreas descubiertas en las que aflora directamente el roquedo gneísico masivo o donde se acumulan masas sueltas y relativamente inestables de clastos angulosos (muy predominantemente de tamaño bloque) resultantes de la fragmentación del mismo. En ellas la cubierta vegetal es extremadamente laxa, limitándose a pequeños grupos de plantas acogidos en fisuras o a ejemplares aislados en huecos entre los bloques más estabilizados. Las especies más frecuentes en la vegetación fisurícola de los roquedales son Dianthus hispanicus, Digitalis thapsi, Saxifraga willkomiana, Hieracium carpetanum, Criptogama crispa, Avenella ibérica y Agrostis rupestris, mientras que en las pedreras sueltas sólo aparecen de forma muy dispersa Agrostis truncatula, Senecio pyrenaicus, Sedum brevifolium y Avenella iberica (Rivas-Martínez et al., 1989 y 1999). La extensión que suman estas áreas en el puerto 

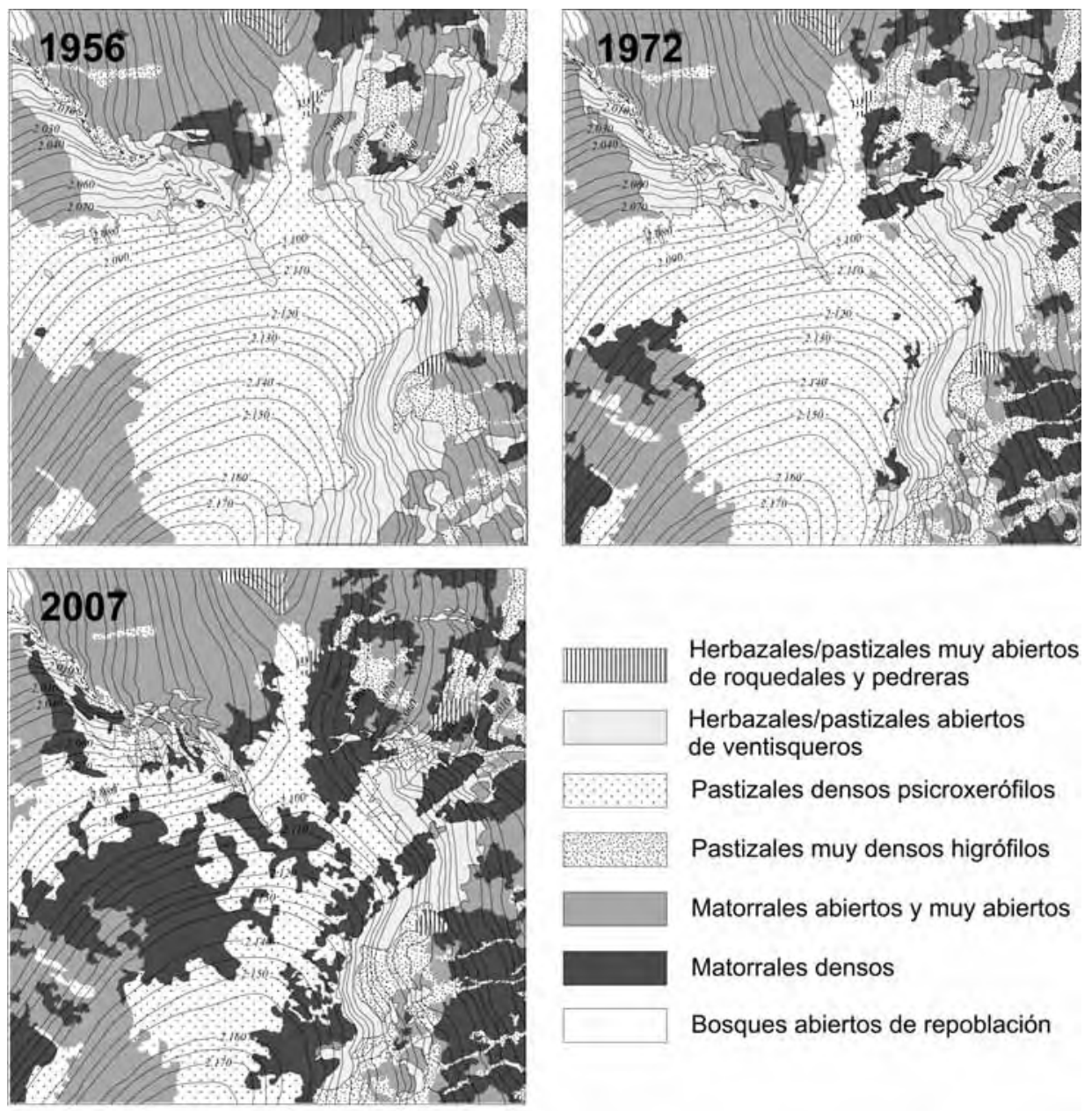

Herbazales/pastizales muy abiertos de roquedales y pedreras

Herbazales/pastizales abiertos de ventisqueros

\section{Pastizales densos psicroxerófilos}

P. Pastizales muy densos higrófilos

Matorrales abiertos y muy abiertos

Matorrales densos

Bosques abiertos de repoblación

Figura 2. Distribución de la vegetación del Puerto de los Neveros en tres fechas representativas del inicio, parte media y final del período de estudio.

de los Neveros es pequeña (en torno al $1 \%$ de la superficie) y se ha incrementado de forma casi imperceptible a lo largo del intervalo temporal considerado (Fig. 4b; Foto 3).

\subsection{Herbazales/Pastizales abiertos de ventisqueros}

Aparecen también en las fotografías aéreas como ámbitos sin recubrimiento vegetal apreciable dentro de los que, a finales de primavera o comienzos de verano, se conservan acumulaciones o retazos más o menos importantes de nieve (Palacios et al., 2003). Si se los reconoce desde tierra, se observa que en ellos aflora un potente manto de alteración con abundantes fragmentos de neis o existe un manto de formaciones 

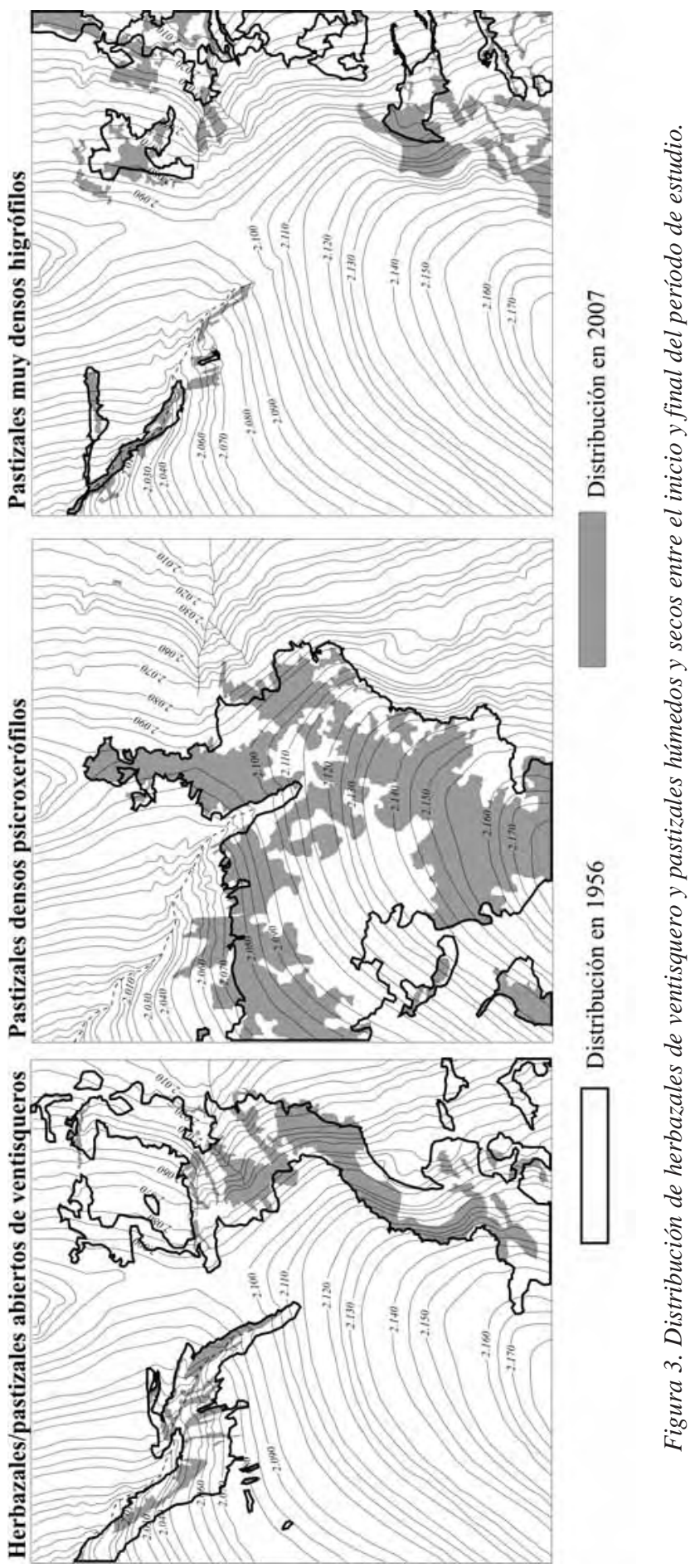


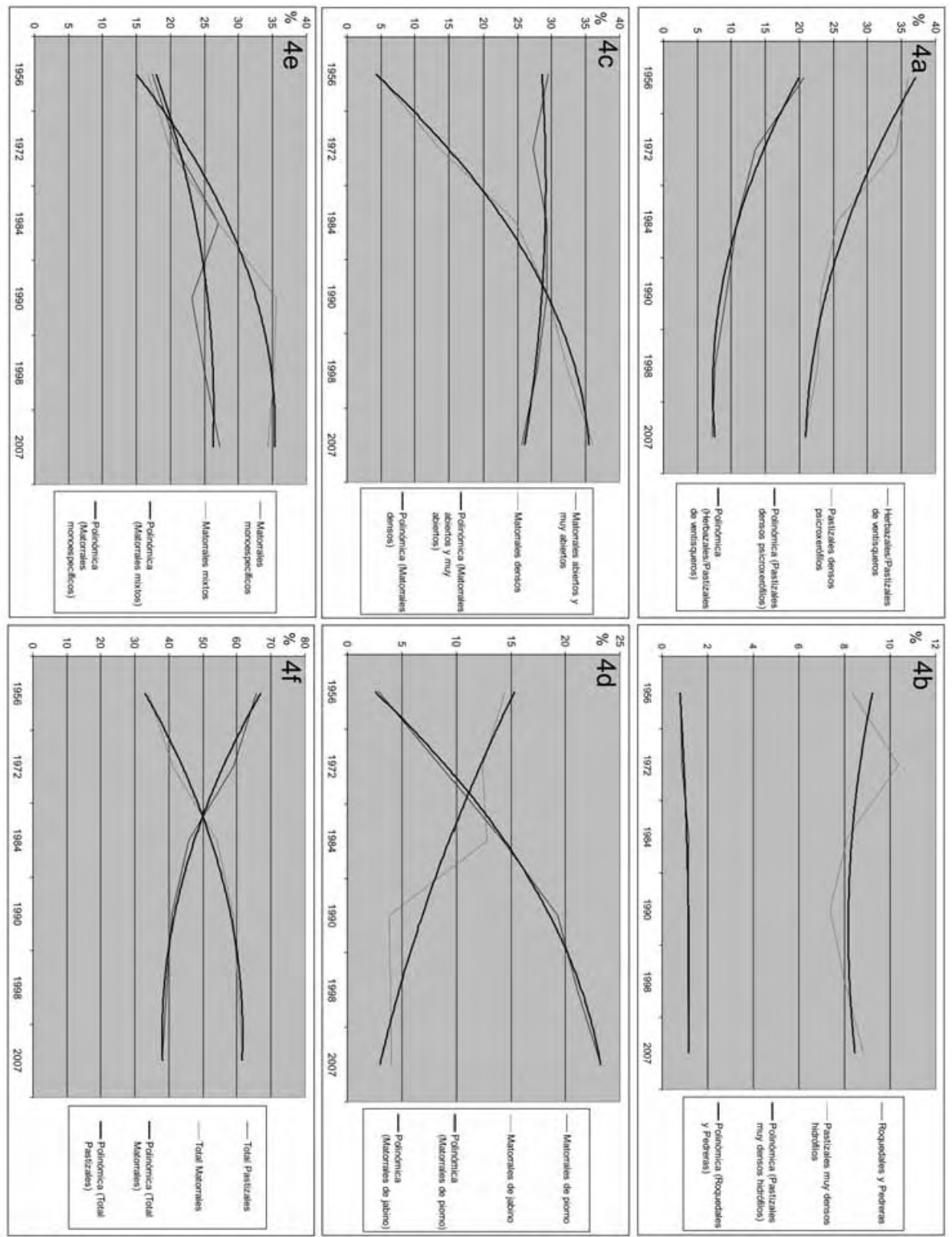

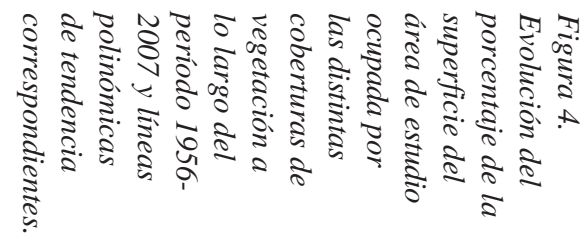




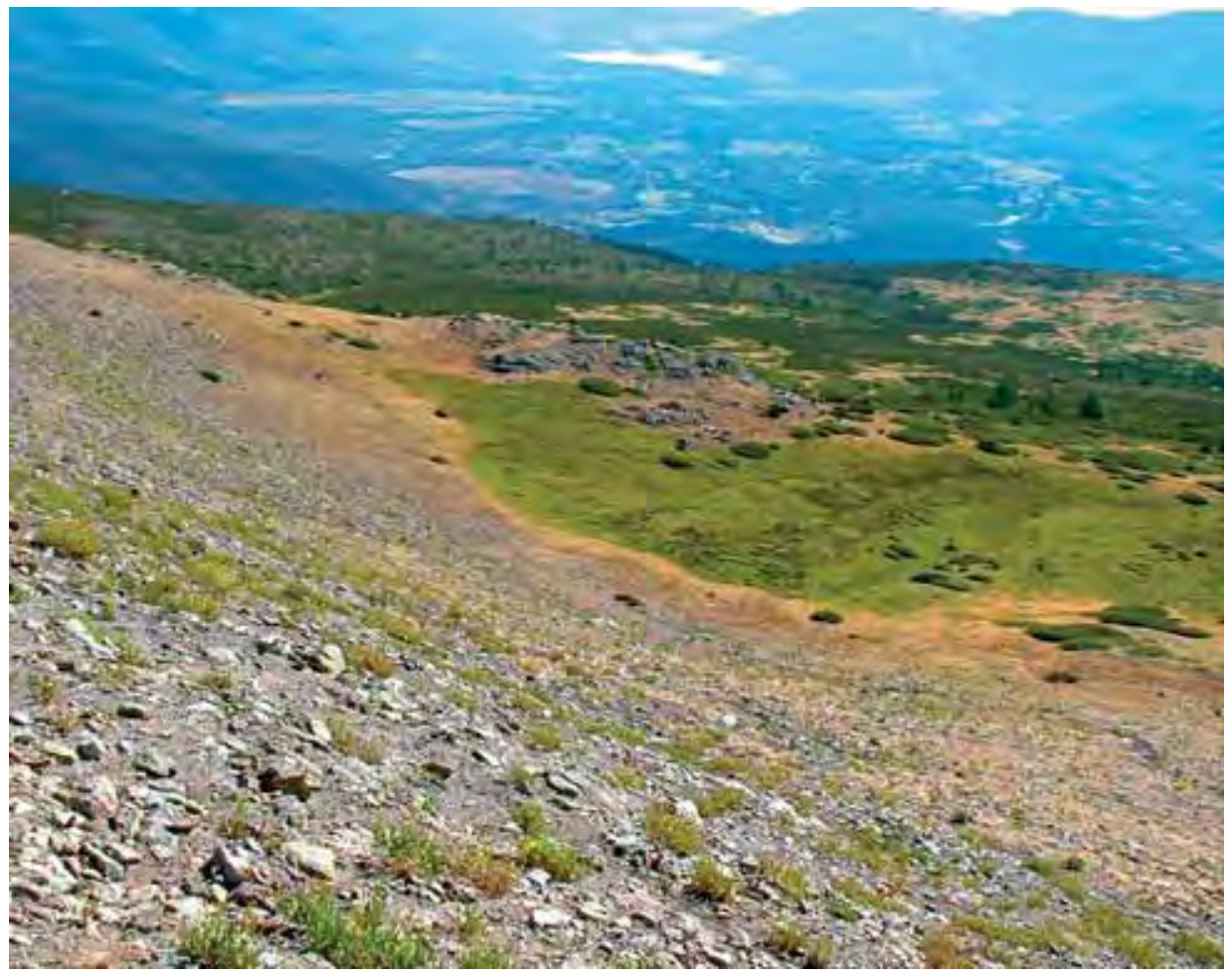

Foto 3. Coberturas de vegetación en el sector oriental del Puerto de los Neveros.

En primer plano Herbazal/Pastizal muy abierto de ventisquero; en segundo plano,

Pastizal muy denso higrófilo ("cervunal"); e inmediatamente tras él, en el asomo rocoso, Herbazal/Pastizal muy abierto de roquedales y pedreras.

coluviales muy mayoritariamente empastadas en cuya fracción gruesa dominan los cantos o los bloques de esta misma litología. Sobre estos materiales se desarrolla un recubrimiento herbáceo muy abierto en el que se mezclan plantas quionófilas rastreras o de pequeña talla como Sedum candollei, Rumex acetosella, Paronychia poligonifolia, Leucantemopsis pallida y Linaria saxatilis, plantas herbáceas de talla media o alta capaces de tolerar una larga duración de la nieve, como Gentiana lutea y Senecio pyrenaicus, y gramíneas adaptadas también a ambientes pedregosos de alta montaña, como Agrostis truncatula, Koeleria caudata y Avenella iberica (Fernández González, 1991; Palacios y García, 1997). Este tipo de vegetación llegaba a ocupar en los años centrales del siglo XX una quinta parte de la superficie del collado. En la actualidad, después de una continuada y rápida disminución, su extensión se ha reducido a menos de la mitad, claramente por debajo de la décima parte del área estudiada, cuya denominación de "Puerto de los Neveros" está cada vez más alejada de la situación actual (Fig. 3 y 4a; Foto 3 ). 


\subsection{Pastizales densos psicroxerófilos ("joragales")}

Son espacios cubiertos por césped denso de muy baja talla y ciclo estacional marcado, claramente reconocibles en la fotografía aérea, que en algunos sectores aparecen limpios de arbustos aunque en la mayor parte de los casos están salpicadas por matas poco desarrolladas de Cytisus carpetanus ("piorno") o por algún ejemplar rastrero de Juniperus alpina ("enebro de montaña" o "jabino"). En dichos espacios, donde afloran mantos de alteración de neis ricos en fracción gruesa, las gramíneas pertenecientes a especies resistentes al frío y al viento pero poco tolerantes a cubiertas nivales espesas y duraderas, entre las que destaca por su abundancia Festuca curvifolia (“joraga”), constituyen pastizales de apreciable densidad, junto con otras especies herbáceas de baja talla capaces también de soportar la dureza del clima de los ambientes más ventosos y desabrigados de la alta montaña (Hieracium vahlii, Jasione crispa, Silene cialiata, Armeria caespitosa y Erysimum penyalarense, entre otras) (Sanz, 1979; Rivas-Martínez et al., 1999). Estos “joragales” psicroxerófilos siempre han ocupado una parte importante del collado, pero han registrado en el período analizado una apreciable y sostenida tendencia a la reducción espacial: al comienzo de éste eran el tipo de vegetación más ampliamente representado en el área de estudio, más de un tercio de cuya superficie colonizaban, mientras que al final del mismo colonizan alrededor de la quinta parte de dicha área, siendo superados en cuanto a extensión por varios tipos de matorrales (Fig. 3 y 4a; Foto 4).

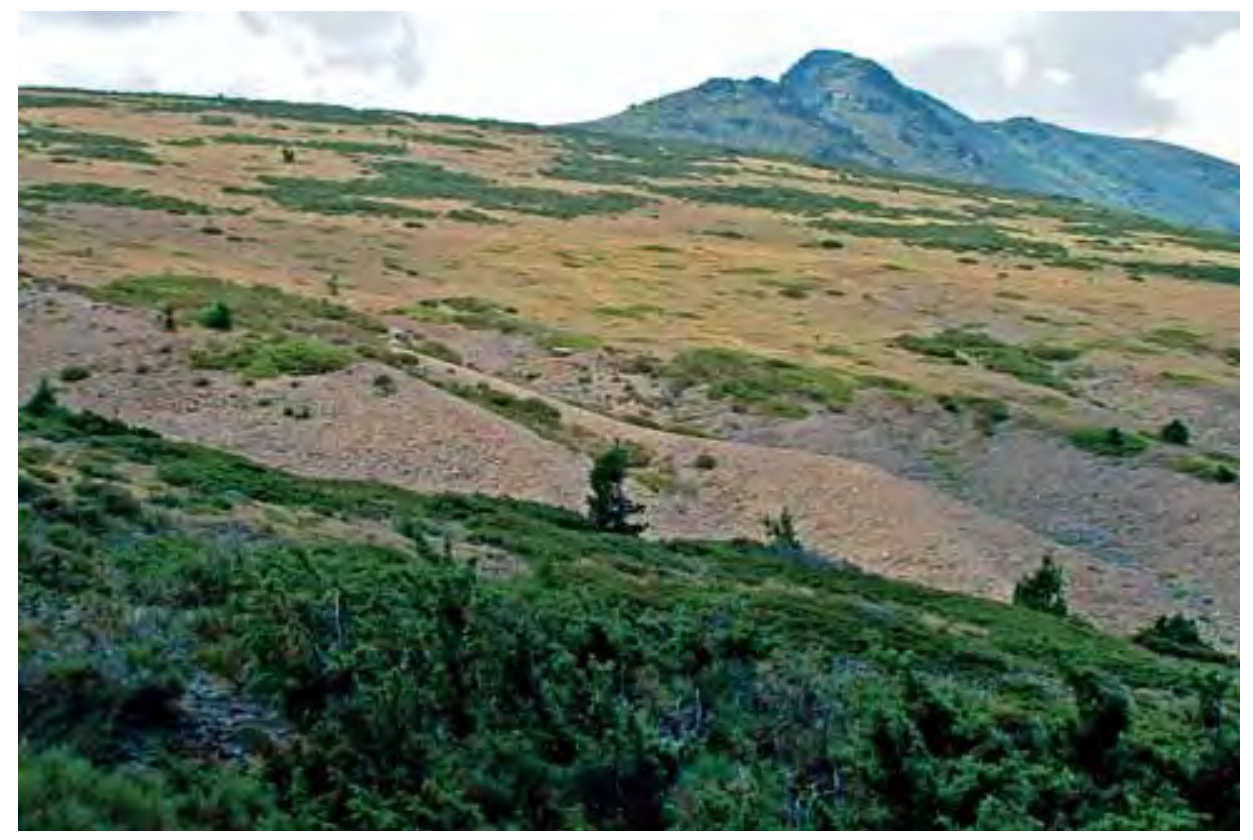

Foto 4. Coberturas de vegetación en la loma culminante del Puerto de los Neveros [vista desde el Noroeste; al fondo Risco Claveles y su enlace con el conjunto montañoso de Peñalara]. Superficies de color ocre claro, Pastizales densos psicroxerófilos ("joragales"); manchas verde oscuro, Matorrales densos de piorno; manchas verde claro, Matorrales densos de jabino. 


\subsection{Pastizales muy densos higrófilos ("cervunales”)}

Se diferencian claramente tanto en la fotografía aérea como sobre el terreno por ser áreas colonizadas por formaciones de gramíneas siempre verdes fuertemente enraizadas en formaciones edáficas de textura y naturaleza turbosas ricas en humedad e incluso localmente saturadas. Estos pastizales, de muy alta densidad, están compuestos por gramíneas de montaña particularmente higrófilas, entre las que destacan por su abundancia Nardus stricta ("cervuno") y Festuca iberica. Estas dos especies dominantes se encuentran acompañadas por Luzula campestris, Hieracium pilosella, Ranunculus bulbosus, Polytrichium juniperinum, Galium rivulare y Trifolium repens, en los sectores no saturados de agua, y por Spagnum sp., Carex nigra, Carex echinata, Viola palustris, Erica tetralix y Drosera rotundifolia, en enclaves pantanosos o próximos a cursos de arroyos (Sanz, 1979; RivasMartínez et al., 1999). La extensión de estos “cervunales", que con mucha frecuencia aparecen salpicados por grandes matas rastreras de Juniperus alpina ("jabino"), es relativamente modesta -entre el 7 y el $10 \%$ de la superficie del área- y se ha mantenido con escasas variaciones a lo largo del período analizado (Fig. 3 y 4b; Foto 3).

\subsection{Matorrales abiertos o muy abiertos}

En las sucesivas coberturas de fotografía aérea del puerto de los Neveros se diferencian con claridad espacios cubiertos por matorrales de mediana o baja densidad, compuestos en unos casos de forma prácticamente exclusiva por Cytisus carpetanus ("piorno") o por Juniperus alpina ("jabino") y, en otros, por una mezcla de ambas especies (Rivas-Martínez et al., 1987; Fernández González, 1991). Se trata de ámbitos en los que los ejemplares o grupos de estos arbustos pertenecientes respectivamente a la familia de las leguminosas y a la familia de las cupresáceas dejan entre sí espacios libres, ocupados sólo por vegetación herbácea, cuya extensión relativa puede llegar a ser tan grande que sitúe a estas formaciones en la transición entre un verdadero matorral y un pastizal psicroxerófilo salpicado de matas. En este estrato herbáceo predominan las gramíneas (sobre todo Avenella iberica, Festuca curvifolia y Koeleria caudata) y se encuentran con frecuencia Rumex suffruticosus y Rumex acetosella (Rivas-Martínez et al, 1999). Los matorrales de este tipo se encuentran sobre todo en sectores de pendiente moderada, colonizando prioritariamente depósitos coluviales de textura media o fina y mantos de alteración homogéneos con pocos afloramientos de roca sana. Ocupan dentro del collado una superficie importante cuyas dimensiones han tenido un margen de variación relativamente estrecho a lo largo del período estudiado (entre el 25 y el 30\% del área) y llegaron a ser en los años ochenta el tipo de vegetación más importante por su extensión. En las décadas anteriores ocuparon el segundo puesto, tras los Pastizales psicroxerífilos, y en las posteriores han sido superados ligeramente por los Matorrales densos de los que se tratará a continuación (Fig. 4c y 5; Foto 6)

Esta sencillez y estabilidad de conjunto encubren, sin embargo, importantes complicaciones estructurales y evolutivas que afectan a las formaciones que -teniendo en cuenta la especie arbustiva dominante-componen este tipo de vegetación. Mientras los matorrales poco densos de piorno o de piorno con jabino han registrado una progresión espacial apreciable (del 15 al 24\%), los matorrales abiertos monoespecíficos de jabino han sufrido una marcada reducción (del 14 al 4\%) (Fig. 4d; Foto 5). 
Matorrales abiertos y muy abiertos

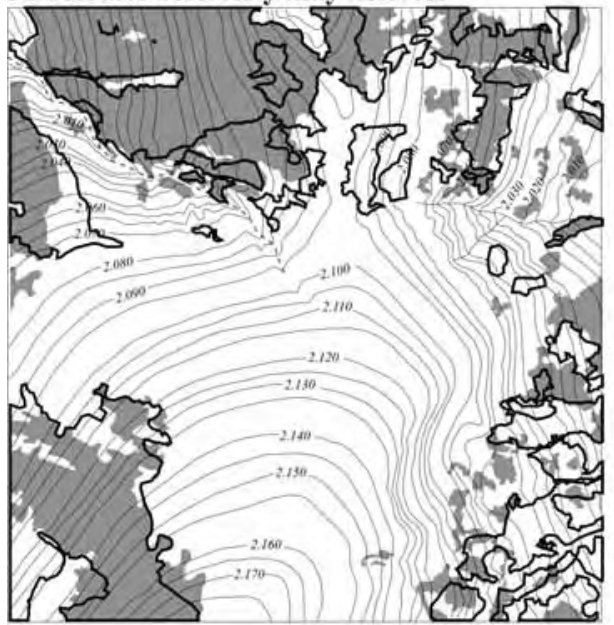

Distribución en 1956

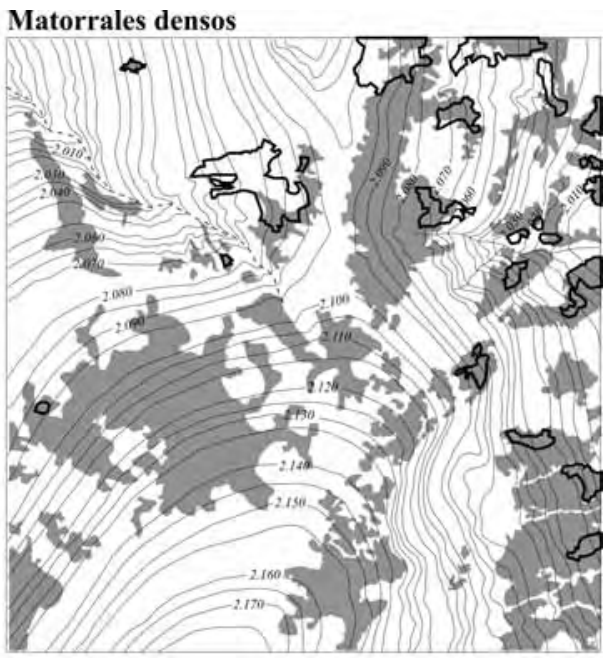

Distribución en 2007

Figura 5. Distribución de matorrales entre el inicio y el final del período estudiado.

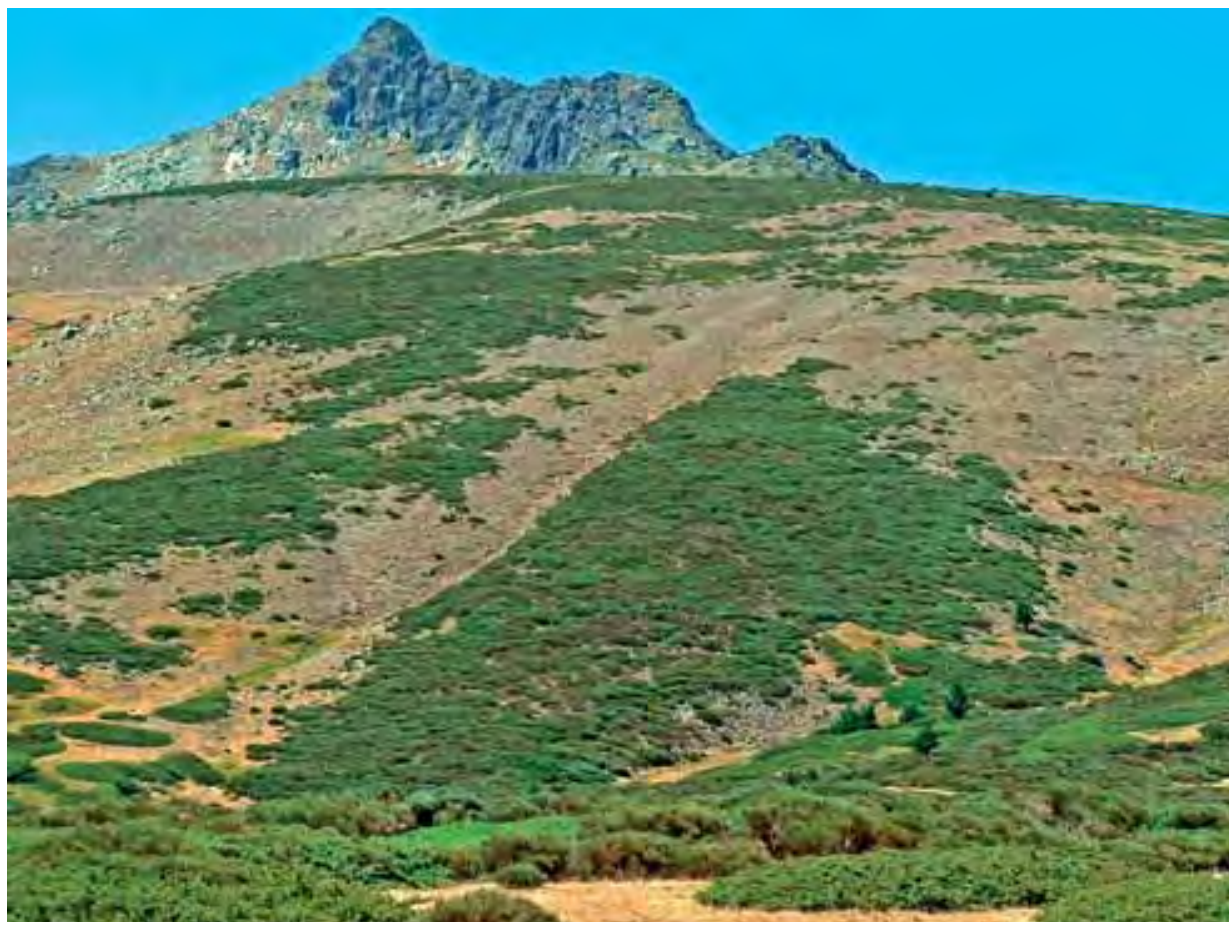

Foto 5. Coberturas de vegetación en el borde Sureste del Puerto de los Neveros Ipróximo al Risco Claveles]. Manchas de color verde, Matorral denso mixto de piorno y jabino; superficies pedregosas de color gris, Herbazal/Pastizal muy abierto de ventisquero. 


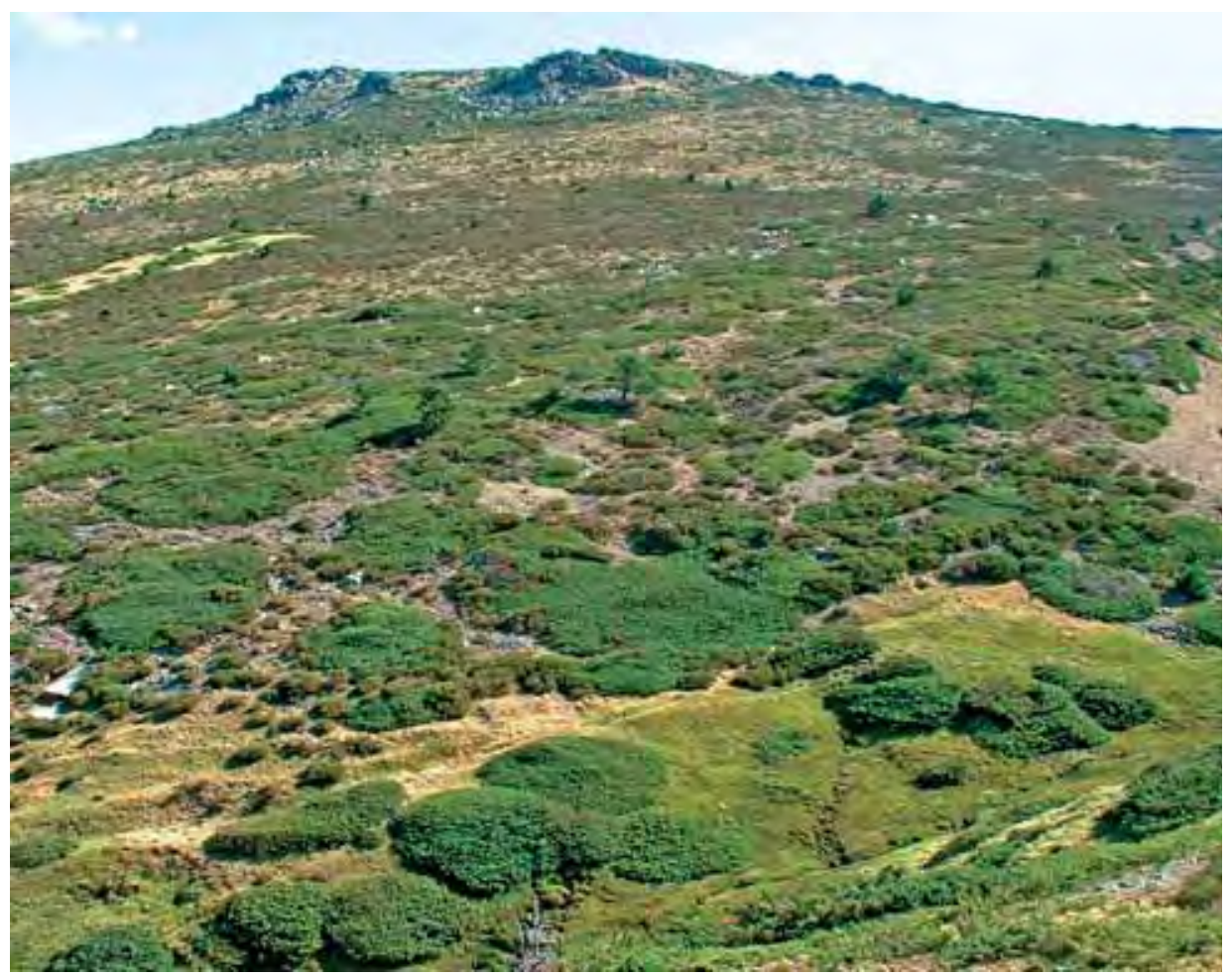

Foto 6. Coberturas de vegetación en el sector Norte del Puerto de los Neveros [rampa de enlace con el Alto del Nevero]. De primer a último plano, Pastizal muy denso higrófilo ("cervunal”), Matorral abierto de jabino y Matorral abierto y muy abierto de piorno.

\subsection{Matorrales densos}

También aparecen en las imágenes aéreas del puerto de los Neveros áreas densamente cubiertas por vegetación arbustiva localizadas mayoritariamente en sectores de ladera de pendiente moderada o alta donde son frecuentes los afloramientos directos del roquedo o los depósitos coluviales incluyen bloques de gran calibre. Si se las reconoce desde tierra, se constata que en ellas dominan las mismas especies de talla arbustiva que en los matorrales de menor densidad antes analizadas: el "piorno" (Cytisus carpetanus) y el "jabino" (Juniperus alpina). Los individuos de éstas, acompañados en algunos casos por matas de Adenocarpus hispanicus ("cambroño" o "codeso"), constituyen masas de fuerte densidad en las que apenas quedan huecos donde puede desarrollarse un estrato herbáceo laxo, pero de notable riqueza florística, en el que tienen una presencia significativa Avenella iberica, Arrenatherum elatius, Festuca curvifolia, Hieracium myriadenum, Thymus praecox, Senecio pyrenaicus, Luzula lactea y Rumex acetosella (Rivas-Martínez, 1987, 1989 y 1999). En conjunto, estos matorrales son desde los años noventa del siglo pasado el tipo de vegetación que ocupa más espacio en el collado obje- 
to de estudio (el 36\% de la superficie total en la actualidad); y también es sin duda el que ha registrado un mayor crecimiento superficial, ya que a mediados del siglo XX su área apenas representaba el 5\% de dicha superficie. Al igual que ocurre en otros sectores ya estudiados de la sierra de Guadarrama, la expansión de estas formaciones arbustivas de alta densidad constituye uno de los principales procesos que se registran en el intervalo temporal de referencia (Fig. 4c y 5; Foto 4).

Lo mismo que en el caso de los matorrales abiertos y muy abiertos, dentro de este tipo de vegetación arbustiva densa la evolución de las formaciones que se pueden diferenciar teniendo en cuenta la abundancia-dominancia de las especies características ha seguido rumbos contrastados. Los matorrales densos monoespecíficos de jabino han tenido siempre una presencia mínima (inferior al 0,2\%), mientras que tanto los matorrales densos de piorno como los matorrales densos mixtos de jabino y piorno (cuyas áreas eran respectivamente del 0,7 y del $3,8 \%$ en 1956) han llegado a ocupar-cada uno- una superficie en torno al $16 \%$ del total después de haber registrado una continuada y fuerte progresión a lo largo del período analizado. Esta progresión ha sido notable en el caso de los matorrales densos mixtos, que han cuadruplicado su extensión, pero ha alcanzado un nivel espectacular en el caso de los piornales densos, que la han multiplicado por 20. Todo pone de manifiesto, pues, que la progresión de Cytisus carpetanus invadiendo el territorio de los pastizales (sobre todo de los psicroxerífilos), penetrando en las áreas inicialmente salpicadas de jabinos y densificando las formaciones de matorral constituye uno de los procesos que más ha participado en el cambio de la estructura espacial de la cubierta vegetal en el puerto de los Neveros (Fig. 4e).

\subsection{Bosques abiertos de repoblación}

En el margen occidental del área cuadrangular seleccionada se encuentra una pequeña superficie repoblada con pino silvestre que enlaza con los bosques de coníferas de la vertiente segoviana de la sierra de Guadarrama (Izquierdo, 2007). Su extensión es mínima (inferior a media hectárea) y, teniendo en cuenta que está influida más por las acciones antrópicas que por las modificaciones del ambiente climático, este tipo de cubierta vegetal no se toma en consideración en el estudio.

\section{Sentido y ritmo de las principales tendencias evolutivas de la cubierta vegetal}

Todos los datos expuestos, procedentes de la interpretación de las sucesivas coberturas de fotografía aérea, permiten apreciar cómo en el puerto de los Neveros se han producido desde mediados del pasado siglo cambios muy significativos en el reparto del territorio entre los diversos tipos de recubrimiento vegetal. Estos cambios han conducido globalmente a una transformación del área de estudio, en la que inicialmente dominaban con claridad las formaciones herbáceas, en un ámbito mayoritariamente colonizado por matorrales: los pastizales y herbazales han reducido su área del 65,8\% en 1956 al 38,0\% en 2007, al tiempo que las formaciones leñosas arbustivas han incrementado la suya del 34,0\% en 1956 al 61,6\% en 2007. Y la indicada progresión de los 
matorrales ha ido acompañada por una creciente y marcada densificación de los mismos: las masas arbustivas cerradas o de alta densidad han pasado de ocupar sólo el 4,5\% del área en 1956 a extenderse por el 36,0\% de ella en 2007. Es de destacar, sin embargo, que en esta evolución progresiva de los matorrales no han participado del mismo modo las dos especies que los constituyen, ya que las formaciones con presencia exclusiva o dominante del "jabino" -casi siempre abiertas o muy abiertas- han sufrido una fuerte reducción de área (del 14,4\% en 1956 al 4,1\% en 2007), mientras que los piornales puros y los matorrales mixtos - de media o alta densidad en la mayor parte de los casos- se han desarrollado profusamente (pasando en conjunto del 19,5\% de la superficie del collado en 1956 al 57,56\% en 2007) (Fig. 4f) (Tablas 2 y 3).

Tabla 2. Superficie ocupada por los tipos de vegetación de matorral según la especie dominante, en las fechas correspondientes a las coberturas de fotografía aérea utilizadas.

\begin{tabular}{|l|c|c|c|c|c|c|}
\hline & $\mathbf{1 9 5 6}$ & $\mathbf{1 9 7 2}$ & $\mathbf{1 9 8 4}$ & $\mathbf{1 9 9 0}$ & $\mathbf{1 9 9 8}$ & $\mathbf{2 0 0 7}$ \\
\hline Matorrales de piorno & $3,39 \mathrm{~h}$ & $10,12 \mathrm{~h}$ & $16,84 \mathrm{~h}$ & $22,77 \mathrm{~h}$ & $24,89 \mathrm{~h}$ & $27,40 \mathrm{~h}$ \\
& $2,86 \%$ & $8,57 \%$ & $14,24 \%$ & $19,30 \%$ & $21,90 \%$ & $23,22 \%$ \\
\hline Matorrales de jabino & $17,05 \mathrm{~h}$ & $14,57 \mathrm{~h}$ & $15,07 \mathrm{~h}$ & $4,55 \mathrm{~h}$ & $4,69 \mathrm{~h}$ & $4,48 \mathrm{~h}$ \\
& $14,45 \%$ & $12,35 \%$ & $12,77 \%$ & $3,85 \%$ & $3,97 \%$ & $4,05 \%$ \\
\hline Matorrales mixtos & $19,66 \mathrm{~h}$ & $23,51 \mathrm{~h}$ & $31,89 \mathrm{~h}$ & $41,99 \mathrm{~h}$ & $41,49 \mathrm{~h}$ & $40,53 \mathrm{~h}$ \\
& $16,66 \%$ & $19,92 \%$ & $27,02 \%$ & $35,58 \%$ & $35,16 \%$ & $34,34 \%$ \\
\hline
\end{tabular}

Tabla 3. Superficie ocupada por los tipos de vegetación de matorral según el carácter de su composición, en las fechas correspondientes a las coberturas de fotografía aérea utilizadas.

\begin{tabular}{|l|c|c|c|c|c|c|}
\hline & $\mathbf{1 9 5 6}$ & $\mathbf{1 9 7 2}$ & $\mathbf{1 9 8 4}$ & $\mathbf{1 9 9 0}$ & $\mathbf{1 9 9 8}$ & $\mathbf{2 0 0 7}$ \\
\hline Matorrales & $20,44 \mathrm{~h}$ & $24,69 \mathrm{~h}$ & $31,91 \mathrm{~h}$ & $27,32 \mathrm{~h}$ & $29,58 \mathrm{~h}$ & $32,18 \mathrm{~h}$ \\
monoespecíficos & $17,32 \%$ & $20,92 \%$ & $27,04 \%$ & $23,15 \%$ & $25,06 \%$ & $27,27 \%$ \\
\hline Matorrales mixtos & $19,66 \mathrm{~h}$ & $23,51 \mathrm{~h}$ & $31,89 \mathrm{~h}$ & $41,99 \mathrm{~h}$ & $41,49 \mathrm{~h}$ & $40,53 \mathrm{~h}$ \\
& $16,66 \%$ & $19,92 \%$ & $27,02 \%$ & $35,58 \%$ & $35,16 \%$ & $34,35 \%$ \\
\hline
\end{tabular}

Dentro del campo de las formaciones herbáceas, que manifiestan en conjunto - como se ha señalado- una clara dinámica regresiva en el período analizado, destacan la notable reducción del área de los pastizales psicroxerófilos de "joraga" (que han pasado de $36,0 \%$ en 1956 al 20,8\% en 2007) y el fuerte retroceso del área ocupada por la vegetación especializada en la colonización de los enclaves más afectados por la presencia duradera de la nieve y por los procesos de nivación. Esta vegetación altamente quionófila propia de los neveros o ventisqueros -que es un valioso indicador de la localización y de la extensión de éstos- ha visto reducido su ámbito del 
20,6\% al 7,2\% de la superficie del puerto. Sólo los densos pastizales higrófilos de "cervuno" y los laxos recubrimientos vegetales de los roquedales y las pedreras no han registrado cambios importantes en las dimensiones de sus áreas.

Las tendencias evolutivas observadas, cuyo sentido y consecuencias se acaban de exponer, no tienen el mismo ritmo ni se han desarrollado de la misma forma. Como se puede apreciar en los correspondientes diagramas y líneas polinómicas, el retroceso del conjunto de las formaciones herbáceas tuvo un ritmo alto en la primera parte del período analizado (hasta los años ochenta) y se ha ralentizado de forma muy significativa a partir de entonces; y correlativamente la progresión del conjunto de los matorrales fue rápida en el primer tramo del período y se ha moderado apreciablemente en la segunda. Puede decirse así que en torno a 1985 ya se había producido en el puerto de los Neveros el paso de un predominio de los pastizales a un predominio de las formaciones arbustivas, el cual después sólo se ha ido consolidando e incrementando lentamente. La densificación de los matorrales, aunque también ha sido algo más rápida en sus primeras décadas, ha sido un proceso que ha mantenido un ritmo de moderado a alto durante todo el período; puede considerarse por ello que mantiene un importante nivel de vigencia en los últimos años y sigue modificando la distribución de las coberturas vegetales en el collado.

La reducción de la superficie ocupada por matorrales monoespecíficos abiertos de jabino se ha realizado de una forma muy diferente, ya que hasta comienzos de los años ochenta tuvo un ritmo muy moderado (incluso con fases de ligera recuperación), se aceleró muy fuertemente a lo largo de la indicada década, para estabilizarse o crecer mínimamente a partir de entonces; se trata en consecuencia de un proceso corto y de elevada intensidad que ha dado paso a una situación de práctica estabilidad. Frente a ello la progresión de los piornales puros ha tenido un ritmo fuerte y sostenido desde los años centrales del siglo XX hasta los primeros años del siglo XXI, pudiendo observarse su vigencia en la actualidad.

Por su parte, la reducción de la superficie de los herbazales quionófilos de ventisquero se ha ido produciendo de forma continua a lo largo de todo el período de referencia, pero con un ritmo inicialmente muy fuerte que ha ido disminuyendo progresivamente, aunque en los últimos tiempos sigue siendo notable. A diferencia de ella, el retroceso de los pastizales psicroxerófilos ha sido continuado pero con importantes cambios de ritmo: muy lento al comienzo, fuerte en las décadas centrales y moderado en los años más recientes.

\section{Caracterización de las condiciones climáticas y de sus modificaciones}

Los cambios en la cubierta vegetal, cuyos caracteres, sentido y ritmo se acaban de exponer, han coincidido en el tiempo con modificaciones en las condiciones climáticas del Guadarrama central, donde se ubica el puerto de los Neveros, que se pueden resumir en una tendencia al incremento de todos los valores termométricos y en una tendencia a la reducción gran parte de los valores pluviométricos y, sobre todo, 
nivométricos. Como se puede apreciar comparando los registros del observatorio meteorológico de Puerto de Navacerrada en la sexta década del siglo XX con los de la primera del siglo XXI, el área se ha hecho menos fría, menos proclive a los descensos nocturnos de temperatura, menos lluviosa y menos afectada por la presencia de la nieve (Alarcón, Martínez y Martínez Molina, 1984; Instituto Nacional de Meteorología, 1995; Agencia Estatal de Meteorología, 2001-2006). Con el objeto de establecer con precisión los caracteres de este cambio en el ambiente climático y de valorar la incidencia del mismo -especialmente de la reducción del tiempo de permanencia de la cubierta nival- en las modificaciones observadas en la cubierta vegetal se han seleccionado, junto con el Número de días de permanencia de la nieve sobre el suelo al año y con el Número de días de permanencia de la nieve sobre el suelo en primavera, las variables climáticas anuales, estacionales y mensuales que presentan un mayor coeficiente de correlación con ella y cuya relación con los condicionamientos ambientales de las plantas y comunidades vegetales de alta montaña ha sido más frecuentemente señalada. Los datos necesarios, correspondientes al período 1951-2006, han sido proporcionados por el citado observatorio de Puerto de Navacerrada y con ellos se han obtenido los valores medios en cada uno de los seis tramos en que se ha dividido el período analizado teniendo en cuenta la fecha de las fotografías aéreas que han servido de base para observar y medir la estructura de la vegetación.

En concreto, se ha operado con las 19 variables climáticas que figuran a continuación: temperatura media anual, temperatura media anual de las máximas, temperatura media anual de las mínimas, temperatura media estacional de primavera, temperatura media estacional de verano, temperatura media estacional de otoño, temperatura media estacional de invierno, temperatura media mensual de abril, temperatura media mensual de mayo, temperatura media mensual de junio, pluviosidad anual, pluviosidad estacional de invierno, número de días de precipitación al año, número de días de nevada al año, número de días de permanencia de la nieve sobre el suelo al año, número de días de nevada en otoño, número de días de nevada en invierno, número de días de nevada en primavera y número de días de permanencia de la nieve sobre el suelo en primavera. Las diez primeras se refieren al nivel y al régimen termométrico y las nueve restantes expresan el volumen de los aportes de agua y nieve y el régimen pluvio-nivométrico.

\subsection{Variables termométricas}

Todos los parámetros estadísticos anuales, estacionales y mensuales seleccionados por su influencia negativa sobre la acumulación y la permanencia de la nieve sobre el suelo, así como sus correspondientes líneas de tendencia, ponen de manifiesto un incremento notable del nivel de las temperaturas en las áreas culminantes de la Sierra de Guadarrama entre 1951 y 2006. Tanto la temperatura media anual como la temperatura media anual de las máximas, después registrar una tendencia muy leve al descenso hasta aproximadamente 1970, han aumentado de forma acelerada para alcanzar en los últimos años del período unos valores que sobrepasan entre un 15 y un $35 \%$ a los que se observaban al comienzo del mismo. Pero lo más significativo es que la tem- 
peratura media anual de las mínimas, con una sostenida y regular tendencia ascendente a lo largo de la totalidad del intervalo temporal considerado, prácticamente se ha duplicado. Teniendo en cuenta que se encuentra $200 \mathrm{~m}$ por encima del emplazamiento del observatorio de puerto de Navacerrada, se puede calcular que en el puerto de los Neveros la temperatura media anual ha pasado de menos de $5,0^{\circ}$ a alrededor de $6,5^{\circ}$, la media anual de las máximas ha crecido de $8,5^{\circ}$ a $10,0^{\circ}$ y la media anual de las mínimas de $0,5^{\circ}$ a algo más de $2,0^{\circ}$.

Igualmente, el nivel térmico medio ha aumentado en todas las estaciones del año, pero lo ha hecho en mayor medida en invierno, lo que es desfavorable para la formación de la cubierta nival, y en primavera, lo que dificulta la permanencia de dicha cubierta. Y es de destacar también que, mientras el incremento de la temperatura media de verano y de la temperatura media de primavera se han producido, con un ritmo fuerte y creciente, sólo a partir de los años setenta del siglo XX (hasta entonces registraron suaves disminuciones), el de la temperatura media de otoño y el de la temperatura media de invierno son resultado de una tendencia positiva regularmente mantenida a lo largo del período considerado.

Por lo que se refiere a los meses de abril, mayo y junio, la evolución los valores termométricos se ha producido en un sentido claramente contrario a la permanencia de la nieve (la mayor parte de la fusión de la cual se produce en ellos). En todos se observa una disminución moderada de la temperatura media mensual hasta 1970-1975 y un fuerte y creciente aumento de la misma desde entonces. Este aumento del nivel térmico medio es particularmente marcado y tiene una especial trascendencia en junio, cuya media mensual ha aumentado alrededor de un $40 \%$.

Con un invierno cada vez menos frío (los $-2,5^{\circ}$ de temperatura media en los años cincuenta del pasado siglo ha pasado a poco más de $-1,0^{\circ}$ en la primera década del presente) y con unos meses de final de primavera y comienzo de verano cada vez más cálidos (la media de junio ha pasado de $10,0^{\circ}$ a aproximadamente $15,0^{\circ}$ ) es lógico que la acumulación y la persistencia de la nieve tiendan a reducirse significativamente en el área de estudio.

Tabla 4. Valores termométricos anuales medios correspondientes a los seis tramos en que se ha dividido el período 1951-2006 (Observatorio de Puerto de Navacerrada).

\begin{tabular}{|l|c|c|c|c|c|c|}
\hline & $\mathbf{1 9 5 1 - 1 9 5 6}$ & $\mathbf{1 9 5 7 - 1 9 7 1}$ & $\mathbf{1 9 7 2 - 1 9 8 3}$ & $\mathbf{1 9 8 4 - 1 9 9 0}$ & $\mathbf{1 9 9 1 - 2 0 0 0}$ & $\mathbf{2 0 0 1 - 2 0 0 6}$ \\
\hline T media anual & 5,75 & 5,83 & 5,92 & 6,74 & 6,97 & 7,70 \\
\hline T max media a. & 9,52 & 9,33 & 9,21 & 10,37 & 10,72 & 10,99 \\
\hline T min media a. & 2,00 & 2,39 & 2,72 & 3,17 & 3,06 & 3,80 \\
\hline
\end{tabular}


Tabla 5. Valores termométricos estacionales medios correspondientes a los seis tramos en que se ha dividido el período 1951-2006 (Observatorio de Puerto de Navacerrada).

\begin{tabular}{|l|c|c|c|c|c|c|}
\hline & $\mathbf{1 9 5 1 - 1 9 5 6}$ & $\mathbf{1 9 5 7 - 1 9 7 1}$ & $\mathbf{1 9 7 2 - 1 9 8 3}$ & $\mathbf{1 9 8 4 - 1 9 9 0}$ & $\mathbf{1 9 9 1 - 2 0 0 0}$ & $\mathbf{2 0 0 1 - 2 0 0 6}$ \\
\hline T media Prim. & 3,53 & 3,23 & 2,89 & 3,53 & 4,67 & 5,60 \\
\hline T media Ver. & 14,13 & 14,10 & 14,03 & 15,40 & 15,48 & 17,32 \\
\hline T media Oto. & 6,76 & 6,73 & 7,15 & 8,15 & 6,94 & 8,01 \\
\hline T media Inv. & $-1,38$ & $-0,88$ & $-0,33$ & $-0,08$ & 0,38 & $-0,09$ \\
\hline
\end{tabular}

Tabla 6. Valores termométricos mensuales medios de abril, mayo y junio correspondientes a los seis tramos en que se ha dividido el período 1951-2006 (Observatorio de Puerto de Navacerrada).

\begin{tabular}{|l|c|c|c|c|c|c|}
\hline & $\mathbf{1 9 5 1 - 1 9 5 6}$ & $\mathbf{1 9 5 7 - 1 9 7 1}$ & $\mathbf{1 9 7 2 - 1 9 8 3}$ & $\mathbf{1 9 8 4 - 1 9 9 0}$ & $\mathbf{1 9 9 1 - 2 0 0 0}$ & $\mathbf{2 0 0 1 - 2 0 0 6}$ \\
\hline T. media abril & 2,70 & 2,46 & 2,03 & 2,41 & 3,28 & 4,80 \\
\hline T. media mayo & 6,75 & 6,82 & 5,96 & 6,80 & 7,53 & 9,08 \\
\hline T. media junio & 11,57 & 11,17 & 11,48 & 12,07 & 12,53 & 16,47 \\
\hline
\end{tabular}

\subsection{Variables pluvio-nivométricas}

La pluviosidad anual, aunque registró un moderado ascenso en las primeras décadas del período considerado, muestra globalmente en el conjunto de él una tendencia decreciente que se ha ido haciendo progresivamente más clara; como consecuencia de ello el volumen medio del agua aportada por las precipitaciones al año se ha reducido en el entorno del puerto de los Neveros alrededor de un $20 \%$ con relación al que se recibía hasta los años setenta. Por su parte, la pluviosidad invernal, que se produce muy mayoritariamente en forma de nieve, ha disminuido en el mismo intervalo temporal algo más de un $30 \%$.

El número anual de días de precipitación y el número anual de días de nevada han sufrido también cambios importantes, mostrando igualmente una suave tendencia al incremento hasta 1975. Con posterioridad a esta fecha el valor de ambos parámetros climáticos ha ido descendiendo, aunque de forma más clara y regular en el caso de las precipitaciones nivales. Éstas han reducido su frecuencia de forma progresiva en más de un $40 \%$, al tiempo que las precipitaciones globalmente consideradas lo han hecho con un ritmo más desigual y en algo menos de un $30 \%$.

Como consecuencia, sin duda, de esta reducción de los aportes pluvio-nivométricos y del incremento de los niveles térmicos antes indicado, la duración anual de la 
nieve sobre el suelo se ha reducido de forma muy apreciable. En el puerto de Navacerrada la persistencia de la cubierta nival durante el año se ha reducido a comienzos del siglo XXI casi a la mitad de la que se registraba a mediados del siglo XX e incluso hasta la década de los setenta. En el puerto de los Neveros, con una altura $200 \mathrm{~m}$ superior, se ha calculado -teniendo en cuenta el altísimo valor del coeficiente de correlación del Número de días de permanencia de la nieve con la Temperatura media anual $(-0,98)$ y con la Temperatura media del mes de junio $(-0,94)$ y aplicando los gradientes termométricos obtenidos a partir de los registros de los sensores automáticos en los últimos seis años (-0,65\%/100, tanto para el conjunto del año como para el indicado mes)- que en el tramo final del período considerado la duración media anual de la nieve sobre el suelo es de 92 días, lo que significa una reducción del 46\% con respecto a la que debió registrarse entre 1951 y 1971 (alrededor de 170 días/año por término medio).

El acortamiento del tiempo de permanencia de la cubierta nival se relaciona también con la frecuencia de las precipitaciones en forma nieve en las estaciones del año donde están presentes, la cual, de acuerdo con los datos proporcionados por el observatorio meteorológico de Puerto de Navacerrada, ha sufrido modificaciones apreciables. Así, el número de días de nevada en otoño ha tenido una tendencia creciente durante la primera mitad del período, entrando después en una fase de retroceso, fuertemente acelerado en los últimos años, que lo ha llevado a un valor medio próximo a la mitad del que llegó a alcanzar en los años sesenta. Por su parte, el número de días de nevada en invierno muestra una línea de tendencia francamente ascendente hasta 1970 y progresivamente descendente desde entonces; como consecuencia de ello la frecuencia de las precipitaciones sólidas en esta estación del año (cuya influencia en la formación de una cubierta nival continua, voluminosa y potencialmente duradera es evidente) se ha reducido casi en un 40\%. La evolución en el trimestre primaveral tiene unos caracteres análogos, ya que el número de días de nevada en primavera (muy importante para acortar o prolongar la permanencia de la nieve) presentó una tendencia creciente hasta los años setenta y ha disminuido con ritmo marcado en las últimas décadas, lo que ha implicado su reducción en una cuantía superior al $50 \%$.

Tabla 7. Volúmenes pluviométricos recibidos por término medio al año y en la estación invernal correspondientes a los seis tramos en que se ha dividido el período 1951-2006

(Observatorio de Puerto de Navacerrada).

\begin{tabular}{|l|c|c|c|c|c|c|}
\hline & $\mathbf{1 9 5 1 - 1 9 5 6}$ & $\mathbf{1 9 5 7 - 1 9 7 1}$ & $\mathbf{1 9 7 2 - 1 9 8 3}$ & $\mathbf{1 9 8 4 - 1 9 9 0}$ & $\mathbf{1 9 9 1 - 2 0 0 0}$ & $\mathbf{2 0 0 1 - 2 0 0 6}$ \\
\hline P anual & 1377,33 & 1447,80 & 1457,92 & 1231,86 & 1209,70 & 1169,64 \\
\hline P invernal & 460,00 & 453,87 & 509,75 & 382,14 & 381,20 & 336,37 \\
\hline
\end{tabular}


Modificaciones recientes de la cubierta nival y evolución de la vegetación supraforestal en la Sierra de Guadarrama...

Tabla 8. Número medio anual de días de precipitación y de nevada en los seis tramos en que se ha dividido el período 1951-2006 (Observatorio de Puerto de Navacerrada).

\begin{tabular}{|l|c|c|c|c|c|c|}
\hline & $\mathbf{1 9 5 1 - 1 9 5 6}$ & $\mathbf{1 9 5 7 - 1 9 7 1}$ & $\mathbf{1 9 7 2 - 1 9 8 3}$ & $\mathbf{1 9 8 4 - 1 9 9 0}$ & $\mathbf{1 9 9 1 - 2 0 0 0}$ & $\mathbf{2 0 0 1 - 2 0 0 6}$ \\
\hline D Precip/año & 132,00 & 158,47 & 150,83 & 138,00 & 146,00 & 106,5 \\
\hline D nieve/año & 64,50 & 80,80 & 80,75 & 73,14 & 68,00 & 44,5 \\
\hline
\end{tabular}

Tabla 9. Número medio anual y primaveral de días de permanencia de la nieve sobre el suelo en los seis tramos en que se ha dividido el período 1951-2006

(Observatorio de Puerto de Navacerrada).

\begin{tabular}{|l|c|c|c|c|c|c|}
\hline & $\mathbf{1 9 5 1 - 1 9 5 6}$ & $\mathbf{1 9 5 7 - 1 9 7 1}$ & $\mathbf{1 9 7 2 - 1 9 8 3}$ & $\mathbf{1 9 8 4 - 1 9 9 0}$ & $\mathbf{1 9 9 1 - 2 0 0 0}$ & $\mathbf{2 0 0 1 - 2 0 0 6}$ \\
\hline Dur nieve/año & 140,83 & 151,47 & 139,83 & 122,00 & 110,80 & 79,9 \\
\hline Dur nieve/prim. & 54,83 & 53,60 & 57,83 & 41,86 & 32,20 & 25,39 \\
\hline
\end{tabular}

Tabla 10. Número medio de días de nevada en otoño, invierno y primavera en los seis tramos en que se ha dividido el período 1951-2006 (Observatorio de Puerto de Navacerrada).

\begin{tabular}{|l|c|c|c|c|c|c|}
\hline & $\mathbf{1 9 5 1 - 1 9 5 6}$ & $\mathbf{1 9 5 7 - 1 9 7 1}$ & $\mathbf{1 9 7 2 - 1 9 8 3}$ & $\mathbf{1 9 8 4 - 1 9 9 0}$ & $\mathbf{1 9 9 1 - 2 0 0 0}$ & $\mathbf{2 0 0 1 - 2 0 0 6}$ \\
\hline D nieve/otoño & 9,00 & 13,20 & 10,50 & 9,86 & 11,20 & 6,00 \\
\hline D nieve/invier. & 34,67 & 39,93 & 37,58 & 35,00 & 32,70 & 23,67 \\
\hline D nieve/prim. & 20,83 & 27,67 & 32,50 & 27,43 & 22,90 & 12,67 \\
\hline
\end{tabular}

\section{Sentido y ritmo de las modificaciones de los parámetros climáticos}

De acuerdo con los datos expuestos, los principales procesos de modificación climática registrados en el área donde se ubica el puerto de los Neveros son el aumento continuado de la temperatura media de invierno y de la temperatura media anual de las mínimas, junto con la disminución progresivamente acelerada en la última parte del período analizado de la duración de la nieve en el conjunto del año y en primavera. También son significativos, marcando tendencias complementarias con las anteriores, el aumento progresivo de la temperatura media de primavera, de la temperatura media anual de las máximas y de la temperatura media del mes de junio y la disminución igualmente progresiva de la duración anual de la nieve y de la pluviosidad invernal. 
Así pues, el análisis estadístico de la evolución de 19 indicadores meteorológicos anuales, estacionales y mensuales a lo largo del período 1951-2006 ha permitido reconocer una tendencia global al incremento en todos los valores termométricos y una tendencia a la disminución en la práctica totalidad de los valores pluviométricos y nivométricos, de modo que a finales de dicho período el ambiente climático de las cumbres y altas laderas del Guadarrama central -donde se ubica el puerto de los Neveroses menos frío, menos lluvioso y está menos afectado por la presencia de la nieve que a mediados del siglo XX. Como consecuencia de los cambios producidos el área analizada se ha hecho globalmente menos fría, menos proclive a los fuertes descensos nocturnos de la temperatura y menos favorable a la persistencia de la cubierta nival y en ella el invierno y la primavera se han ido haciendo menos fríos y con una más corta persistencia de la nieve sobre el suelo. Todo ello conforma una modificación ambiental capaz de incidir en la evolución de la vegetación supraforestal.

\section{Resultados: correlación entre la evolución espacial de los tipos y facies vegetales y la modificación de los parámetros climáticos}

Con el objeto de valorar con la mayor precisión posible el nivel de covariación existente entre los parámetros climáticos y la extensión de los diversos componentes de la cubierta vegetal se han obtenido los Índices de Correlación que figuran en las Tablas 11 y 12. La primera de ellas se refiere a los tipos y subtipos genéricos de vegetación (formaciones herbáceas y formaciones arbustivas; matorrales monoespecíficos y matorrales mixtos; etc) y la segunda a las 6 facies de vegetación básicas que se han reconocido en las sucesivas coberturas de fotografía aérea del Puerto de los Neveros, dejando fuera a los pinares de repoblación por su escasísima superficie, por su práctica estabilidad y por su vinculación casi exclusiva a factores antrópicos.

Conforme al contenido de la primera de dichas tablas, la temperatura media de invierno, la temperatura media anual de las mínimas, la temperatura media anual, la duración anual de la nieve, la duración de la nieve en primavera y la temperatura media anual de las máximas son las variables climáticas más altamente relacionadas con la dinámica espacial de las grandes tipos de vegetación: el valor medio de su correlación con la superficie ocupada por éstos (positiva en unos casos y negativa en otros) se sitúa entre 0,75 y 0,91 . Vienen a continuación, la temperatura media de verano y la pluviosidad anual, cuya correlación media alcanza o supera ligeramente el 0,70. En el otro extremo, como parámetros climáticos menos influyentes a esta escala de los grandes tipos genéricos, se encuentran el número de días de nevada en primavera, el número de días de nevada en otoño, el número de días de nevada al año y el número de días de precipitación al año, ninguno de los cuales llega al 0,35 de correlación media. Todo indica pues que el calentamiento climático, de forma directa y a través de la disminución del período de permanencia de la nieve, ha sido y es el factor principal de las grandes tendencias evolutivas de la cubierta vegetal en el área de estudio, teniendo, por el contrario, una escasa influencia en ello la reducción de la frecuencia de las nevadas y del intervalo temporal en que se producen. 
Tabla 11. Índices de correlación entre los 19 parámetros climáticos considerados y la superficie de los tipos y subtipos genéricos de vegetación que se han diferenciado en el puerto de los

Neveros teniendo en cuenta la forma de vida de las plantas [1: Herbazales y pastizales.

2: Matorrales], la composición florística [3: Matorrales monoespecíficos. 4: Matorrales mixtos] y la especie dominante [5: Matorrales de piorno. 6: Matorrales de jabino]. En negrita los índices (positivos o negativos) iguales o superiores a 0,65.

\begin{tabular}{|c|c|c|c|c|c|c|}
\hline & 1 & 2 & 3 & 4 & 5 & 6 \\
\hline $\mathrm{T}$ media anual & $-0,82$ & $\mathbf{0 , 8 2}$ & 0,63 & 0,84 & $\mathbf{0 , 8 9}$ & $-0,91$ \\
\hline T media anual de las máximas & $-0,74$ & 0,74 & 0,45 & $\mathbf{0 , 8 1}$ & $\mathbf{0 , 8 2}$ & $-0,93$ \\
\hline T media anual de las mínimas & $-0,92$ & 0,92 & $\mathbf{0 , 8 0}$ & 0,89 & 0,95 & $-0,87$ \\
\hline $\mathrm{T}$ media de primavera & $-0,55$ & 0,55 & 0,42 & 0,57 & 0,66 & $-0,71$ \\
\hline $\mathrm{T}$ media de verano & $-0,72$ & 0,72 & 0,55 & 0,74 & $\mathbf{0 , 8 0}$ & $-0,83$ \\
\hline T media de otoño & $-0,70$ & $\mathbf{0 , 7 0}$ & 0,50 & 0,74 & 0,71 & $-0,71$ \\
\hline T media de invierno & $-0,96$ & 0,96 & $\mathbf{0 , 8 0}$ & 0,95 & 0,94 & $-0,85$ \\
\hline T media del mes de abril & $-0,44$ & 0,43 & 0,38 & 0,43 & 0,55 & $-0,57$ \\
\hline $\mathrm{T}$ media del mes de mayo & $-0,46$ & 0,45 & 0,35 & 0,47 & 0,58 & $-0,64$ \\
\hline $\mathrm{T}$ media del mes de junio & $-0,57$ & 0,57 & 0,54 & 0,54 & 0,66 & $-0,61$ \\
\hline Pluviosidad anual & 0,71 & $-0,70$ & $-0,37$ & $-\mathbf{0 , 8 0}$ & $-0,78$ & 0,92 \\
\hline Pluviosidad invernal & 0,62 & $-0,62$ & $-0,31$ & $-0,72$ & $-0,73$ & $\mathbf{0 , 9 0}$ \\
\hline Días de precipitación al año & 0,32 & $-0,31$ & $-0,22$ & $-0,33$ & $-0,38$ & 0,43 \\
\hline Días de nevada al año & 0,32 & $-0,31$ & $-0,22$ & $-0,33$ & $-0,41$ & 0,47 \\
\hline Duración anual de la nieve & 0,75 & $-0,75$ & $-0,61$ & $-0,76$ & $-0,82$ & $\mathbf{0 , 8 1}$ \\
\hline Duración de la nieve en primavera & 0,74 & $-0,74$ & $-0,51$ & $-0,78$ & $-0,83$ & 0,90 \\
\hline Días de nevada en otoño & 0,34 & $-0,33$ & $-0,29$ & $-0,33$ & $-0,37$ & 0,35 \\
\hline Días de nevada en invierno & 0,54 & $-0,54$ & $-0,44$ & $-0,54$ & $-0,62$ & 0,62 \\
\hline Días de nevada en primavera & 0,16 & $-0,15$ & $-0,04$ & $-0,20$ & $-0,28$ & 0,40 \\
\hline
\end{tabular}


Tabla 12. Índices de correlación entre los 19 parámetros climáticos considerados y la superficie de las 6 facies de vegetación básicas que se han diferenciado en el puerto de los Neveros, sin contar los Bosques abiertos de repoblación [1: Roquedales y pedreras.

2: Ventisqueros. 3: Pastizales psicroxerófilos. 4: Pastizales higrófilos.

5: Matorrales abiertos y muy abiertos. 6: Matorrales densos].

En negrita los índices (positivos o negativos) iguales o superiores a 0,65.

\begin{tabular}{|c|c|c|c|c|c|c|}
\hline & 1 & 2 & 3 & 4 & 5 & 6 \\
\hline $\mathrm{T}$ media anual & 0,69 & $-0,78$ & $-0,84$ & $-0,25$ & $-0,66$ & 0,86 \\
\hline T media anual de las máximas & 0,58 & $-0,68$ & $-0,76$ & $-0,34$ & $-0,55$ & $\mathbf{0 , 7 7}$ \\
\hline T media anual de las mínimas & $\mathbf{0 , 8 4}$ & $-0,89$ & $-0,92$ & $-0,25$ & $-0,62$ & 0,95 \\
\hline $\mathrm{T}$ media de primavera & 0,40 & $-0,53$ & $-0,58$ & $-0,04$ & $-0,77$ & 0,62 \\
\hline T media de verano & 0,60 & $-0,68$ & $-0,75$ & $-0,17$ & $-0,72$ & $\mathbf{0 , 7 7}$ \\
\hline T media de otoño & 0,68 & $-0,60$ & $-0,73$ & $-0,45$ & $-0,23$ & 0,69 \\
\hline $\mathrm{T}$ media de invierno & $\mathbf{0 , 8 9}$ & $-0,94$ & $-0,93$ & $-0,44$ & $-0,30$ & 0,94 \\
\hline T media del mes de abril & 0,31 & $-0,43$ & $-0,48$ & 0,10 & $-0,83$ & 0,52 \\
\hline T media del mes de mayo & 0,30 & $-0,47$ & $-0,48$ & 0,13 & $-0,86$ & 0,54 \\
\hline T media del mes de junio & 0,49 & $-0,54$ & $-0,62$ & $-0,01$ & $-0,78$ & 0,64 \\
\hline Pluviosidad anual & $-0,55$ & 0,61 & $\mathbf{0 , 7 3}$ & 0,43 & 0,45 & $-0,72$ \\
\hline Pluviosidad invernal & $-0,43$ & 0,60 & 0,63 & 0,18 & 0,62 & $-0,67$ \\
\hline Días de precipitación al año & $-0,28$ & 0,18 & 0,40 & 0,21 & 0,47 & $-0,36$ \\
\hline Días de nevada al año & $-0,23$ & 0,22 & 0,39 & 0,08 & 0,62 & $-0,38$ \\
\hline Duración anual de la nieve & $-0,66$ & 0,68 & 0,79 & 0,27 & 0,65 & $-0,79$ \\
\hline Duración de la nieve en primavera & $-0,57$ & 0,10 & 0,21 & 0,19 & 0,69 & $-0,79$ \\
\hline Días de nevada en otoño & $-0,36$ & 0,16 & 0,43 & 0,33 & 0,32 & $-0,36$ \\
\hline Días de nevada en invierno & $-0,47$ & 0,44 & 0,61 & 0,20 & 0,65 & $-0,59$ \\
\hline Días de nevada en primavera & $-0,02$ & 0,10 & 0,21 & $-0,08$ & 0,67 & $-0,23$ \\
\hline
\end{tabular}


La segunda tabla de Coeficientes de Correlación pone de manifiesto que también la temperatura media de invierno y la temperatura media anual de las mínimas (que registran valores medios en torno al 0,75 ) son las variables climáticas más altamente relacionadas con la dinámica espacial de las seis facies básicas de vegetación reconocidas en el puerto, seguidas a corta distancia por la temperatura media anual, la duración anual de la nieve, la temperatura media de verano y la temperatura media anual de las máximas. Pero es de destacar que, en este caso, la temperatura media anual y la duración anual de la nieve son las que tienen una influencia más generalizada, presentando un nivel de covariación significativo (por encima de 0,60 o de - 0,60 ) con todas o casi todas las formaciones vegetales. Igualmente los parámetros climáticos menos influyentes a esta escala son el número de días de nevada en otoño, el número de días de nevada al año y el número de días de precipitación al año, ninguno de los cuales pasa del 0,35 de correlación media, remarcando la primacía del factor termométrico y de los factores nivométricos condicionados por él sobre los factores estrictamente vinculados a las precipitaciones en forma de nieve.

Si se analizan a la luz de los resultados expuestos las principales modificaciones y tendencias de la vegetación antes indicadas, se puede concluir que la Progresión de los matorrales y el correlativo Retroceso de los herbazales y pastizales, que caracteriza globalmente la evolución de la cubierta vegetal que coloniza el puerto de los Neveros, deriva fundamentalmente del aumento de la T media de invierno, la $\mathrm{T}$ media anual de las mínimas y la T media anual y de la disminución de la duración anual de la nieve y la duración de la nieve en primavera que se han registrado entre 1951 y 2006 . Y esta misma combinación de tendencias evolutivas del clima da razón de la Progresión de los matorrales densos y de la Progresión de los matorrales de piorno que definen igualmente el cambio de la vegetación a lo largo de dicho período. Con ella, aunque sustituyendo la disminución de la duración de la nieve en primavera por el aumento de la T media de verano en un caso y por el aumento de la T media anual de las máximas en otro, se relacionan también otros dos cambios decisivos en el área: el Retroceso de las formaciones herbáceas quionófilas que marcan la superficie de los ventisqueros o neveros que dieron nombre al collado y el Retroceso de los pastizales psicroxerófilos, dominantes en él a mediados del siglo XX.

Otras modificaciones de menor rango, pero también significativas, de la cubierta vegetal se relacionan con combinaciones de tendencias climáticas diferentes en mayor o mayor medida de la combinación calentamiento/reducción de la permanencia de la nieve que se acaba de describir. Así el Retroceso de los matorrales de jabino se relaciona prioritariamente con el aumento de la T media anual de las máximas y de la T media anual y con la disminución de la pluviosidad anual, de la pluviosidad invernal y de la duración de la nieve en primavera. La Progresión de los matorrales mixtos, por su parte, no se vincula de forma preferente con ninguna variable referente a la nieve, ya que se adapta en mayor medida al aumento de la T media de invierno, de la T media anual de las mínimas, de la T media anual y de la T media anual de la máximas y a la disminución de la pluviosidad anual. Pero el proceso evolutivo más claramente diferenciado del resto es el Retroceso de de los matorrales abiertos y muy abiertos, ligado sobre todo al calenta- 


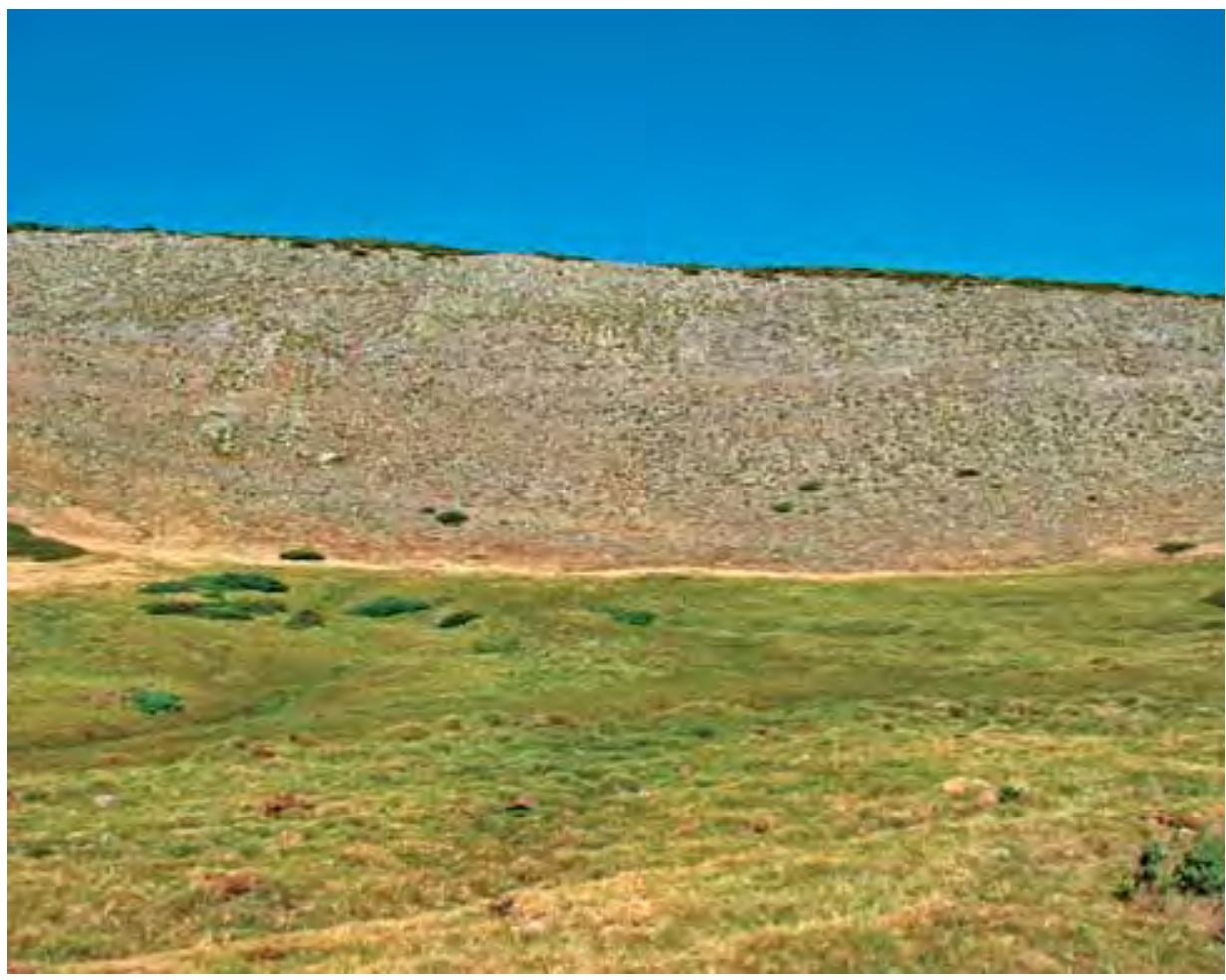

Foto 7. Ventisquero en el borde oriental del Puerto de los Neveros, bien delimitado y con su cubierta vegetal (Herbazal/Pastizal muy abierto) escasamente invadida por plantas de las formaciones que lo enmarcan por arriba (Matorral denso de piorno) y por abajo (Pastizal muy denso higrófilo).

miento del clima en primavera y verano: sus coeficientes de correlación más elevados lo vinculan ante todo con el aumento de la T media de mayo, de la $\mathrm{T}$ media de abril, de $\mathrm{T}$ media de junio, de la $\mathrm{T}$ media de primavera y de la $\mathrm{T}$ media de verano y con la disminución de la duración de la nieve en primavera (Fotos 7 y 8).

\section{Discusión: Comparación con la cuenca de la Condesa-Valdemartín}

El alto valor de los índices de correlación obtenidos y la básica analogía de las líneas de tendencia de la evolución de los parámetros climáticos más importantes y de la variación las dimensiones relativas de los elementos de la cubierta vegetal ponen de manifiesto que ésta ha acompañado a la modificación de aquéllos también en sus cambios de ritmo y de sentido durante los casi sesenta años analizados. Ello permite afirmar que -como se ha dicho- el reajuste dimensional de las facies vegetales en el puerto de los Neveros ha estado condicionado en gran medida por la evolución del clima en las últi- 


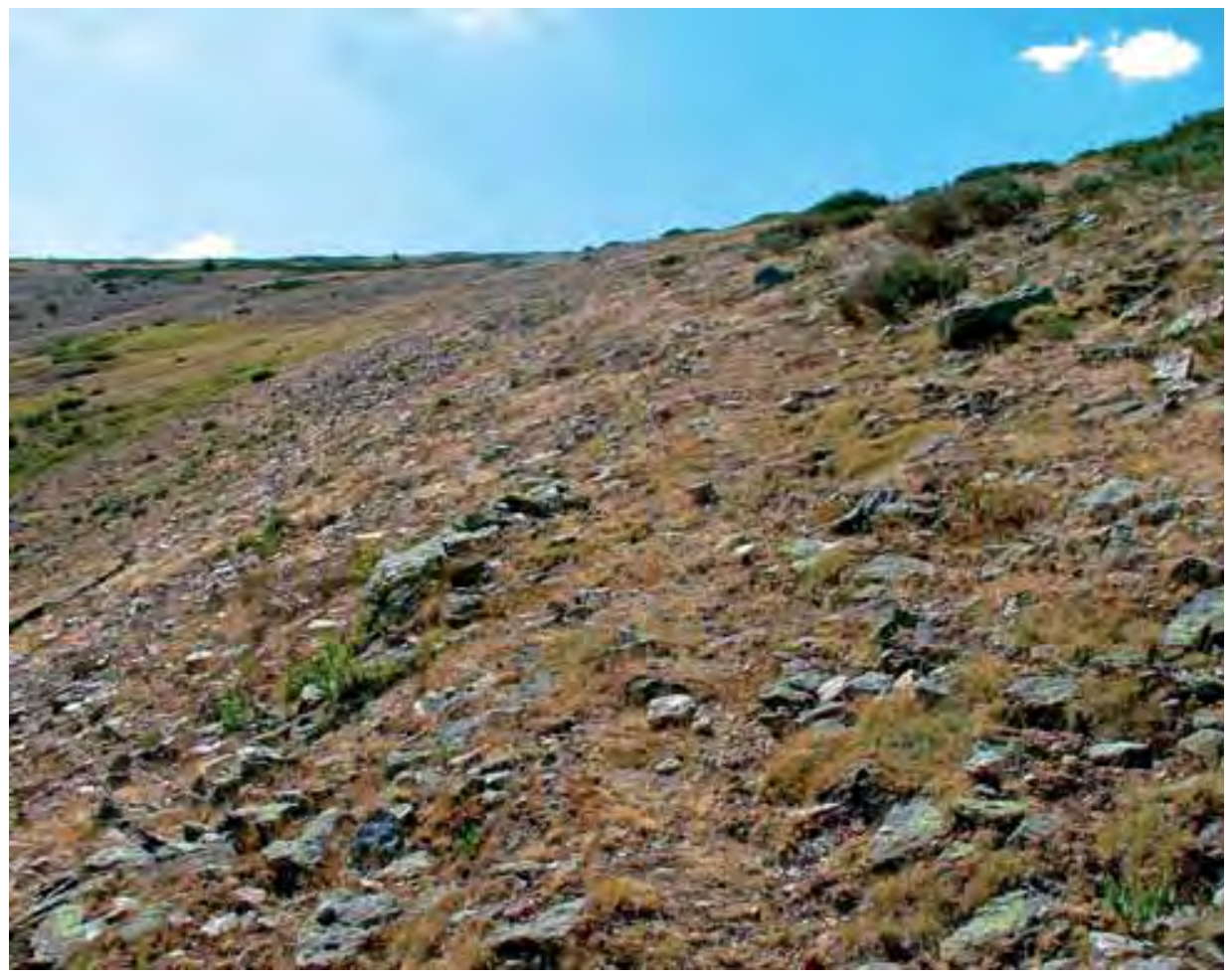

Foto 8. Ventisquero en el borde occidental del Puerto de los Neveros, con límites difusos y con su cubierta vegetal (Herbazal/Pastizal muy abierto) invadida por plantas de las formaciones que lo enmarcan por arriba (Matorral denso de piorno) y por abajo (Pastizal muy denso higrófilo).

mas décadas. La influencia sobre dicho reajuste de cambios de carácter antrópico, como el abandono de la explotación de la nieve (que implicaría el cese de actividades tendentes a prolongar su permanencia en los ventisqueros) y la disminución de la carga ganadera (con la correlativa reducción de las acciones favorables a la conservación o ampliación de los pastizales) no se puede descartar, pero en todo caso ha de tener un valor muy secundario o complementario (Campos y Carrera, 2005; Troitiño, 2005).

La extracción de la nieve para su comercialización en La Granja y Segovia, centrada sólo en una parte muy reducida del área, se había extinguido a principios del siglo XX tras alcanzar su máxima intensidad en el XIX (Corella, 1988) y la ganadería, que hasta finales del XVIII había sido más intensiva y predominantemente lanar, ya se limitaba mucho antes de comenzar el período estudiado a un número reducido de cabezas de vacuno y equino en semilibertad, capaces de sobrevivir en un ámbito tan elevado, cubierto por la nieve durante tanto tiempo y dotado de unos pastos de tan escasa calidad (Casas Torres, 1943). En este sistema de uso ganadero extensivo tradicional, ampliamente difundido por 
las altas laderas y cumbres de las sierras de Guadarrama y de Gredos, se incluía la quema de matorrales compuestos por leguminosas (en concreto de los piornales), pero no con la finalidad de transformar su área en pastizal sino de rejuvenecerlos, incrementando de este modo la abundancia y la accesibilidad de sus flores y de sus frutos ("vainas"), que constituían un complemento alimenticio imprescindible para el ganado; no parece pues que estos incendios más o menos controlados fueran los responsables de la reducida extensión de las formaciones arbustivas hace sesenta años ("El que quema piornos siembra piornos" es un dicho frecuente en las sierras de Madrid y Ávila), ni que su cese en las seis últimas décadas, al poderse disponer de otros piensos artificiales, haya sido la causa de la progresión espacial de los matorrales de piorno, hoy dominantes en el puerto (Luceño, 1998; Luceño y Vargas, 1991). En todo caso -teniendo en cuenta la capacidad de adaptarse con rapidez a las modificaciones ambientales que ha mostrado la cubierta vegetal no sólo en él, sino en otros sectores del Guadarrama- la desaparición del aprovechamiento de la nieve en los ventisqueros y de las quemas de matorrales ya habrían sido respondidas o asimiladas por la vegetación a mediados del siglo pasado.

Es de destacar además que la evolución de la cubierta vegetal en el puerto de los Neveros presenta, en sus líneas generales, el mismo sentido que en la cercana cuenca de la Condesa-Valdemartín, objeto de un análisis análogo por parte de los autores (Muñoz y García, 2004): dentro de ambos territorios el área de los matorrales ha crecido a costa del ocupado por las formaciones herbáceas, han progresado los matorrales densos y han retrocedido los de moderada o escasa densidad y ha crecido la superficie de las formaciones arbustivas dominadas por el piorno al tiempo que se ha reducido la de las dominadas por el jabino; también en ambos ha disminuido la extensión de los herbazales de ventisquero. La excepción en cuanto a sentido corresponde a los pastizales psicroxerófilos, regresivos en el puerto de los Neveros y que en la cuenca de la Condesa aumentan su área, y los pastizales higrófilos, estables en el primero y regresivos en la segunda.

La diferencia entre ellos radica en la intensidad de los cambios y en la importancia de sus consecuencias. En el puerto de los Neveros todas las modificaciones de la cubierta vegetal han sido más rápidas y marcadas, implicando con frecuencia un desplazamiento de posición de los componentes de la misma; por el contrario, en la cuenca de la Condesa-Valdemartín los procesos de avance o retroceso de las diversas formaciones vegetales han tenido un ritmo y una intensidad más moderados, sin implicar casi nunca una alteración del rango de cada una de ellas. Así, mientras en el primero la progresión espacial de los matorrales los ha hecho pasar del 34 al $62 \%$ y los ha llevado a arrebatar con rapidez a los pastizales la posición dominante que inicialmente tenían, en la segunda el crecimiento del área ocupada por formaciones arbustivas ha sido del 66 al $71 \%$ y ha reforzado el rango de tipo genérico de vegetación mayoritario, que ya ostentaba. Del mismo modo, los matorrales densos han pasado en el puerto del 4 al 36\%, superando en cuanto a extensión a los matorrales de media o baja densidad que a comienzos del período considerado tenían un área claramente mayor, al tiempo que en la alta cuenca su crecimiento ha sido del 20 al 28\%, acortando su diferencia con los matorrales abiertos y muy abiertos pero sin arrebatarlos su rango mayoritario. Por lo que se refiere al avance de los piornales, las diferencias de intensidad entre los dos ámbitos de referencia son 
también marcadas (su área ha crecido del 3 al 23\% en los Neveros y del 44 al $51 \%$ en la Condesa-Valdemartín) e igualmente sólo en el primero los ha llevado a superar a los matorrales de jabino y arrebatarlos su inicial primacía; en el segundo dicho avance los ha consolidado en la posición prioritaria que ya tenían. La reducción de los herbazales de ventisquero, muy significativa en ambos enclaves de alta montaña, es igualmente más marcada en el puerto de los Neveros -donde han pasado del 21 al 7\% de la superficie y han quedado por debajo de los pastizales higrófilos, a los que superaban con claridad a mediados del siglo XX- que en la cuenca de la Condesa-Valdemartín -donde ha pasado del 10 a 5\%, ocupando siempre una superficie inferior a la de los cervunales-.

Tanto en la una como en otra área las modificaciones de la cubierta vegetal se relacionan de forma prioritaria con el aumento de la temperatura media anual de las mínimas, de la temperatura media de invierno y de la temperatura media anual y con la disminución de la duración anual de la nieve. La discordancia más evidente está en el hecho de que la misma modificación global del ambiente climático ha coincidido con un crecimiento del área de los pastizales psicroxerófilos en la cuenca de la Condesa-Valdemartín, mientras que en el puerto de los Neveros lo ha hecho con una reducción significativa de ésta.

Probablemente la causa de esta diferencia -y también de la desigual intensidad y ritmo de los cambios, a la que ya se ha hecho referencia- sea la configuración topográfica de uno y otro enclave: moderadamente desnivelada (207 m de desnivel) y con pendientes relativamente suaves (12\% de pendiente media), en el puerto, y fuertemente desnivelada (554 m de desnivel) y con topografía escarpada ( $20 \%$ de pendiente media), en la alta cuenca. También ha de influir sin duda su respectiva localización en un collado abierto a E y W y en una ladera de sotavento orientada al SE.

\section{Conclusión}

En las áreas supraforestales culminantes de la sierra de Guadarrama, dentro de la más elevada de las cuales se encuadra el puerto de los Neveros, se han producido modificaciones significativas del clima a lo largo de la segunda mitad del siglo XX y los primeros años del siglo XXI, a las que la cubierta vegetal -constituida por plantas herbáceas y arbustivas adaptadas al frío y, en mayor o menor medida, a la nieve- parece haber sido capaz de responder variando de forma significativa la extensión de la superficie ocupada por cada una de sus formaciones o facies principales. Esta variación, cuyo sentido y dimensiones pueden observarse comparando las fotografías aéreas de 1956 y 2007, se relaciona fundamentalmente con el aumento de las temperaturas (sobre todo de las medias invernales y de las mínimas anuales) y con el acortamiento del tiempo de permanencia de la cubierta nival sobre el suelo, pero está influida también por el incremento del nivel térmico en verano y primavera y por la disminución de la persistencia de la nieve en esta estación del año.

Como consecuencia de ella en el puerto de los Neveros los matorrales han pasado a ser el tipo genérico de vegetación mayoritario y han incrementado progresivamente su 
densidad, al tiempo que su composición florística se ha modificado como consecuencia del fuerte incremento de la presencia y la abundancia de una de sus especies características, el piorno. Por el contrario, la superficie colonizada por formaciones herbáceas, que era mayoritaria a comienzos del período considerado, se han reducido casi a la mitad y dentro de ella el retroceso más marcado ha afectado al tipo de cubierta vegetal más específicamente relacionado con la presencia voluminosa y duradera de la nieve, el herbazal abierto de ventisquero, cuya extensión se ha reducido a una tercera parte de la que ocupaba a mediados del pasado siglo; pero también los pastizales psicroxerófilos, adaptados a cubiertas nivales de menor espesor y persistencia, han registrado un retroceso muy apreciable. Por su parte, las formaciones más fuertemente vinculadas a los caracteres del sustrato, como los densos pastizales higrófilos ("cervunales") de los enclaves encharcados de turbera y los pastizales laxos de las pedreras y los roquedales neísicos, no han visto modificada apreciablemente la extensión de su área.

Descartados o ponderados muy a la baja los posibles factores antrópicos, se reafirma la conclusión de que las modificaciones del ambiente climático y del tiempo de permanencia de la nieve han sido el motor de los cambios registrados en distribución de la vegetación del área de estudio en las últimas seis décadas. Nada permite asegurar, sin embargo, que dichas modificaciones sean definitivas y no es posible descartar que a medio plazo pueda producirse un cambio de tendencia más propicio al mantenimiento de la nieve sobre el suelo y la correlativa reversión de algunos de los procesos que han afectado a la cubierta vegetal del puerto de los Neveros.

\section{Agradecimientos}

Este trabajo ha sido realizado dentro del marco de las actividades del Grupo de Investigación "Geografía Física de Alta Montaña” financiado por la Universidad Complutense de Madrid. Damos las gracias al Prof. David Palacios Estremera por su constante apoyo y sus consejos y por su aportación de material fotográfico.

\section{Referencias bibliográficas}

Agencia Estatal de Meteorología (2001-2006). Datos climáticos del observatorio meteorológico Madrid "Puerto de Navacerrada", Años 2001-2006 [recogidos en la página Web Tutiempo.net/clima].

Alarcón López, S., Martínez Martínez, M. T., Martínez Molina, I. (1984). Climatología de Puerto de Navacerrada, Instituto Nacional de Meteorología, Madrid.

Andrés, N., García Romero, A., Muñoz, J., Palacios, D. (2007a). Control of snow cover duration in geomorphologic and biogographic dynamics in Mediterranean mountains: Manzanares valley head, Sierra de Guadarrama (Spain). Zeitschrift fur Geomorphologie, 51, Suppl. 2: 91-111. 
Andrés, N., García Romero, A., Muñoz, J., Palacios, D. (2007b). La vegetación del ventisquero de la Condesa (Sierra de Guadarrama, Madrid) y sus condicionantes termo-nivales. Boletín de la Asociación de Geógrafos Españoles, 44: 29-52.

Andrés, N., PALAcios, D. (2004). Interrelación nieve/geomorfología en la sierra de Guadarrama: altas cuencas del ventisquero de La Condesa y Valdemartín. Cuadernos de Investigación Geográfica, 30: 85-116.

BallantTyne, C. K. (1985). Nivation landforms and snowpatch erosion on two massifs in the Northern Highlands of Scotland, Scottish Geographic Magazine, 10: 40-49.

Billings, W. D., Bliss, L. C. (1959). An alpine snowbank environment and its effects on vegetation, plant development and productivity. Ecology, 40: 388-397.

Campos Palacín, P., Carrera Troyano, M. (2005). Actividad económica y conservación de la naturaleza en parques nacionales: reflexiones para un parque nacional de Guadarrama. En La Sierra de Guadarrama. Diagnóstico de un territorio. Fundación para la Investigación y el Desarrollo Ambiental, pp. 143-179, Madrid.

Casas Torres, J. M. (1943). Sobre la geografía humana del Valle del Lozoya. Estudios Geográficos, 13: 781-827.

Corella SuÁrez, P. (1988). El comercio de la nieve y del hielo en la provincia de Madrid. En: Establecimientos tradicionales madrileños. Cuaderno VIII, Periferia de Madrid y pueblos de la Comunidad. Cámara de Comercio e Industria, pp. 229-240, Madrid.

DALY, C. (1984). Snow distribution patterns in the alpine krummholz zone. Progress in Physical Geography, 8(2): 157-173.

Durán Montejano, L. (2007). Meteorología de montaña en el Parque Natural de Peñalara. En: Quintas Jornadas Científicas del Parque Natural de Peñalara y del Valle de El Paular, Vol. I, pp. 29-42.

FERnÁNDEZ GonZÁLEZ, F. (1991). La vegetación del valle del Paular (Sierra de Guadarrama, Madrid). Lazaroa, 12: 153-272.

Fernández Troyano, L. (1990). Los pasos históricos de la sierra de Guadarrama, Colegio de Ingenieros de Caminos, Canales y Puertos, Madrid.

Gavilán, R., Fernández González, F., Blasic, C. (1998). Climatic classification and ordination of the Spanish Sistema Central: relationships with potential vegetation. Plant Ecology, 139: 1-11.

Instituto Nacional de Meteorología (1995). Valores normales y estadísticos de estaciones principales (1961-1990). Observatorio de Madrid "Puerto de Nacavacerrada”, INM, Madrid.

Instituto Nacional de Meteorología (2002). Observatorio Meteorológico de Madrid "Puerto de Navacerrada". En: Valores normales y estadísticos de los observatorios meteorológicos principales (1971-2000). Volumen 4. Madrid, Castilla La Mancha y Extremadura, INM, pp. 67-86, Madrid. 
IZQuierdo, J. L. (2007). Cartografía de la vegetación del Parque Natural de Peñalara y su zona periférica de protección. En: Quintas Jornadas Científicas del Parque Natural de Peñalara y del Valle de El Paular, Comunidad de Madrid, Vol. 1, pp. 83-94, Madrid.

KÖRNER, C. (1999). Alpine plant life. Springer-Verlag, Berlín.

LuCEÑo, M. (1988). Flores de Gredos. Caja de Ahorros de Ávila. Ávila.

Luceño, M., Vargas, P. (1991). Guía botánica del Sistema Central Español. Ed. Pirámide, Madrid.

Manuel ValdÉs, C. (1996). Tierras y montes públicos en la Sierra de Madrid: sectores central y meridional. Ministerio de Agricultura, Pesca y Alimentación, Madrid.

Marcos, F. J., PAlacios, D. (2004). Efectos de la nieve y de la temperatura del suelo en la actividad geomorfológica: primeros resultados de su monitorización en la Sierra de Guadarrama (España). Boletín de la Real Sociedad Española de Historia Natural, 99 (1-4): 25-36.

MAs HeRnÁndez, R. (1998). El territorio. En: Madrid y la Sierra de Guadarrama, (Martínez de Pisón, E., Dir.). Museo Municipal, pp. 37-77, Madrid.

Muñoz JimÉneZ, J., GARCíA Romero, A. (2004). Modificaciones climáticas y evolución de la cubierta vegetal en las áreas culminantes de la Sierra de Guadarrama (Sistema Central Español) durante la segunda mitad del siglo XX. Las altas cuencas del Ventisquero de la Condesa y Valdemartín. Cuadernos de Investigación Geográfica, 30: 117-146.

NyberG, R. (1991). Geomorphic processes at snowpatch sites in the Abisko Mountains, northern Sweden. Zeischrift fur Geomorphologie, 35(3): 321-343.

Palacios, D., Andrés, N. (2000). Morfodinámica supraforestal actual en la Sierra de Guadarrama y su relación con la cubierta nival: el caso de Dos Hermanas-Peñalara. En Procesos y formas periglaciares en la montaña mediterránea (Peña, J.L., Sánchez Fabre, M., Lozano, M.V., Eds.), Instituto de Estudios Turolenses, pp. 235264, Teruel.

Palacios, D., Andrés, N. (2007). Relación entre dinámica nival y erosión en el Parque Natural de Peñalara y áreas próximas. En: Quintas Jornadas Científicas del Parque Natural de Peñalara y del Valle de El Paular, Comunidad de Madrid, Vol. 1, pp. 95-137, Madrid.

Palacios, D., Andrés, N., Luengo, E. (2003). Distribution and effectiveness of nivation in mediterranean mountains: Peñalara (Spain). Geomorphology, 54: 157-178.

Palacios, D., Andrés, N., Luengo, E. (2004). Tipología y evolución de los nichos de nivación en la Sierra de Guadarrama, España. Boletín de la Real Sociedad Española de Historia Natural, 99 (1-4): 141-158.

Palacios, D., García, M. (1997a). The influence of nival erosion on the distribution of high mountain vegetation to snow cover: Peñalara, Spain, Catena, 30: 1-40. 
Palacios, D., García, M. (1997b). The influence of geomorphologic heritage on present nival erosion: Peñalara, Spain. Geografiska Annaler, 79/A(1-2): 25-40.

Pintado, A., García, L. (2007). Influencia de la cubierta nival en el microclima y en la vegetación de alta montaña en el Parque Natural de Peñalara. En: Quintas Jornadas Científicas del Parque Natural de Peñalara y del Valle de El Paular. Comunidad de Madrid, Vol. 1, pp. 139-147, Madrid.

Rivas-Martínez, S., Belmonte, D., Cantó, P., Fernández González, F., Fuente, V., Moreno, J. M., SÁnchez Mata, D., García SAncho, L. (1987). Piornales, enebrales y pinares oromediterráneos (Pino-Cytision oromediterranei) en el Sistema Central. Lazaroa, 7: 13-124.

Rivas-Martínez, S., Cantó, P., Fernández González F., Navarro, C., Sánchez MatA, D. (1989). Sinopsis de la vegetación saxícola del Sistema central. Facultad de Farmacia (Universidad Complutense), Madrid.

Rivas-Martínez, S., Cantó, P., Fernández González, F., Molina, J. A., Pizarro, J. M., SÁnchez MatA, D. (1999). Sinopsis of the Sierra de Guadarrama vegetation, Itinera Geobotánica, 13: 189-206.

SANZ, C. (1979). El mosaico de geofacies supraforestales en la zona más elevada de la Sierra de Guadarrama. En: VI Coloquio de Geografía. Asociación de Geógrafos Españoles, pp. 243-248, Palma de Mallorca.

SAnz, C. (1988). El relieve del Guadarrama oriental. Comunidad de Madrid (Consejería de Política Territorial), Madrid.

Sanz-Elorza, M., Dana, E. D., GonzÁlez, A., Sobrino, E. (2003). Changes in highmountain vegetation of the Central Iberian Peninsula as a probable sign of Global warming. Annals of Botany, 92: 273-280.

Servicio Meteorológico Nacional (1976). Relación de valores normales correspondientes a Observatorios Principales con datos del período 1931-60. SMN (policop.), Madrid.

Troitiño, M. A. (2005). El territorio del Guadarrama: procesos de cambio, tensiones y conflictos. En: La sierra de Guadarrama. Diagnóstico de un territorio. Fundación para la Investigación y el Desarrollo Ambiental, pp. 87-120, Madrid.

U.G.S.D. (2001). ILWIS 3.0 Academic User's Guide, Enschede, Aerospace Survey and Earth Sciences (ITC).

Valenzuela Rubio, M. (1977). Urbanización y crisis rural en la Sierra de Madrid. Instituto de Estudios de Administración Local, Madrid. 